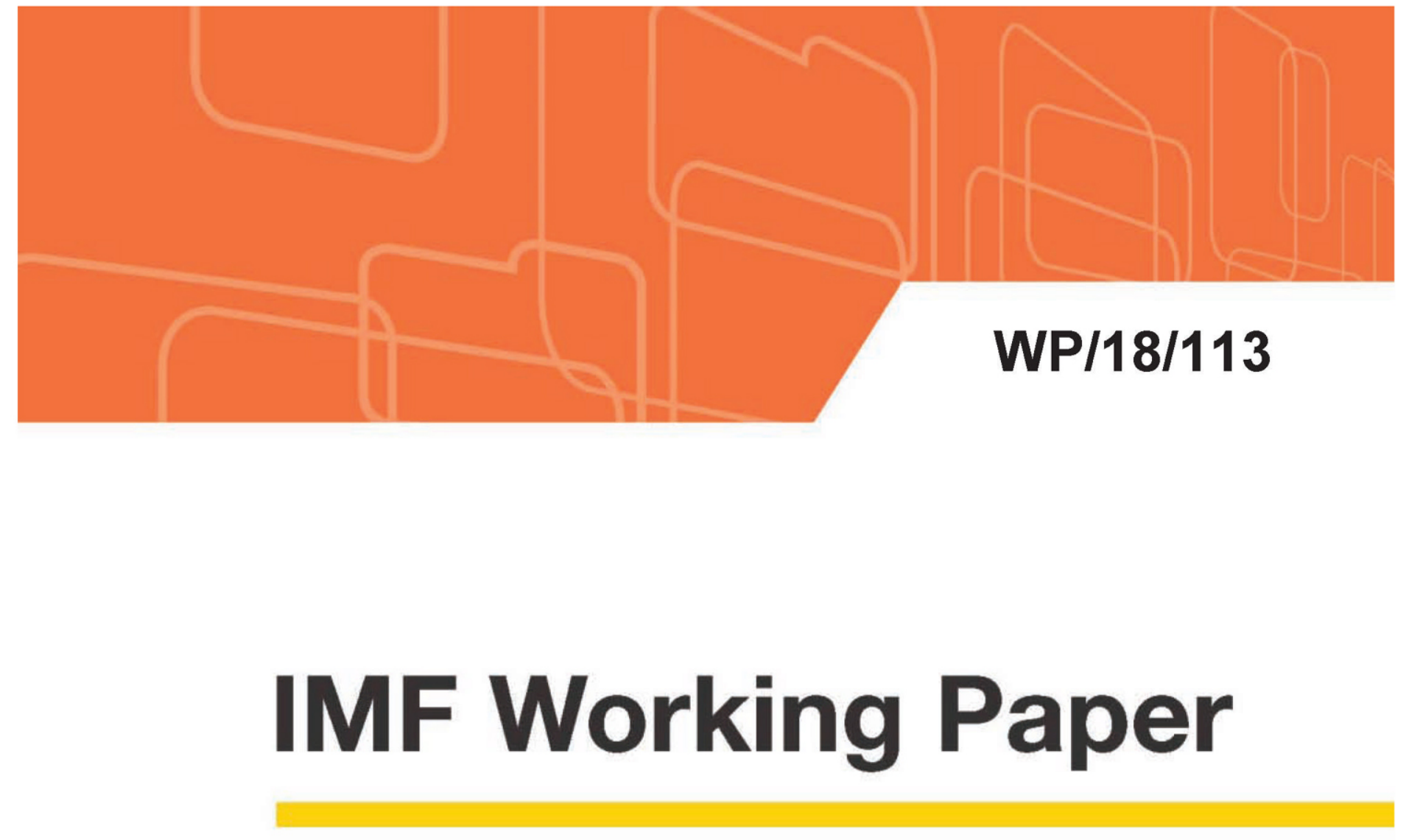

\title{
Evolution of the Global Financial Network and Contagion: A New Approach
}

by Yevgeniya Korniyenko, Manasa Patnam, Rita Maria del Rio-Chanona, and Mason A. Porter

IMF Working Papers describe research in progress by the author(s) and are published to elicit comments and to encourage debate. The views expressed in IMF Working Papers are those of the author(s) and do not necessarily represent the views of the IMF, its Executive Board, or IMF management.

I N T E R N A T I O N A L M O N E T A R Y F U N D 


\section{WP/18/113}

\section{IMF Working Paper}

\section{Evolution of the Global Financial Network and Contagion: A New Approach}

by Yevgeniya Korniyenko, Manasa Patnam, Rita Maria del Rio-Chanona, and Mason A. Porter

IMF Working Papers describe research in progress by the author(s) and are published to elicit comments and to encourage debate. The views expressed in IMF Working Papers are those of the author(s) and do not necessarily represent the views of the IMF, its Executive Board, or IMF management.

I N T ER N A T I O N A L M O NETAR Y F U N D 


\title{
IMF Working Paper
}

Strategy, Policy, and Review Department

\section{Evolution of the Global Financial Network and Contagion: A New Approach ${ }^{1}$}

\section{Prepared by Yevgeniya Korniyenko, Manasa Patnam, Rita Maria del Rio-Chanona ${ }^{2}$, and Mason A. Porter ${ }^{3}$}

Authorized for distribution by Vikram Haksar

May 2018

\section{IMF Working Papers describe research in progress by the author(s) and are published to} elicit comments and to encourage debate. The views expressed in IMF Working Papers are those of the author(s) and do not necessarily represent the views of the IMF, its Executive Board, or IMF management.

\begin{abstract}
This paper studies the interconnectedness of the global financial system and its susceptibility to shocks. A novel multilayer network framework is applied to link debt and equity exposures across countries. Use of this approach — that examines simultaneously multiple channels of transmission and their important higher order effects - shows that ignoring the heterogeneity of financial exposures, and simply aggregating all claims, as often done in other studies, can underestimate the extent and effects of financial contagion. The structure of the global financial network has changed since the global financial crisis, impacted by European bank's deleveraging and higher corporate debt issuance. Still, we find that the structure of the system and contagion remain similar in that network is highly susceptible to shocks from central countries and those with large financial systems (e.g., the USA and the UK). While, individual European countries (excluding the UK) have relatively low impact on shock propagation, the network is highly susceptible to the shocks from the entire euro area. Another important development is the rising role of the Asian countries and the noticeable increase in network susceptibility to shocks from China and Hong Kong SAR economies.

JEL Classification Numbers: C45, F34, F42, F65, G15.
\end{abstract}

Keywords: Financial contagion, spillovers, network analysis.

Author's E-Mail Addresses: maria.delriochanona@balliol.ox.ac.uk; ykorniyenko@imf.org; mpatnam@imf.org; mason@math.ucla.edu

\footnotetext{
${ }^{1}$ The authors would like to thank Vikram Haksar, Murtaza Husain Syed, Helene Poirson Ward, Doyne Farmer, Mariano Beguerisse Dias, Celine Rochon, the Institute for New Economic Thinking complexity economics group for their feedback, and Chengyu Huang for excellent research assistance. All errors and omissions are our own.

${ }^{2,3}$ Rita Maria del Rio-Chanona is a DPhil student at the Department of Mathematics of the University of Oxford and acknowledges funding from Conacyt-SENER for this work. Mason Porter is a Professor at the Department of Mathematics, UCLA.
} 
I. Introduction $\ldots \ldots \ldots \ldots \ldots$

II. Related Literature Overview . . . . . . . . . . . . . . . . $\underline{6}$

III. Descriptive Analysis of the Global Financial Network . . . . . . . . . . . . . $\underline{8}$

A. Data for Networks . . . . . . . . . . . . . . . . $\underline{8}$

B. Conjunctural Analysis of Global Financial Network Using Multiplex Networks

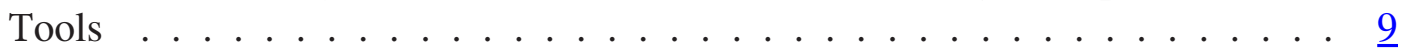

1. Basic measures of network structure ............. . . $\underline{9}$

2. PageRank centrality ................... 10

IV. Contagion: Methodology and Results . . . . . . . . . . . . . . . . $\underline{16}$

A. Threshold Contagion Model: Methodology . . . . . . . . . . . . . $\underline{16}$

B. Contagion in the Global Financial Network: Simulation Results . . . . . . . . . $\underline{17}$

C. Contagion Dynamics in the Global Financial Network . . . . . . . . . . . .20

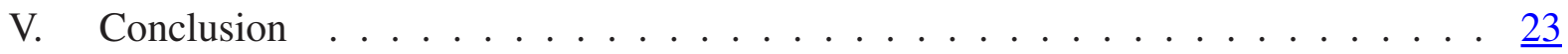

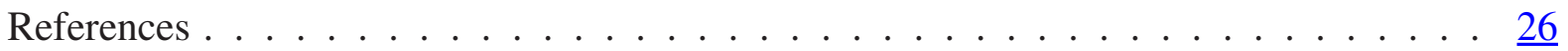

Appendices

A. Immediate Countries Affected Due to Shocks $\ldots \ldots \ldots \ldots$

B. The Multilayer Network Framework . . . . . . . . . . . . . . $\underline{32}$

B.1. Multilayer network formalism and introduction of notation . . . . . . . . . $\underline{32}$

B.2. Mapping of data into the multiplex network . . . . . . . . . . . . $\underline{32}$

B.3. The aggregated network . . . . . . . . . . . . . .

B.4. Structural network measures . . . . . . . . . . . . . $\underline{34}$

C. Multiplex Contagion Model and Simulation . . . . . . . . . . . . 36

D. Other Results of Centrality Measures . . . . . . . . . . . . . . . 38

D.1. Multiplex hubs and authorities ranking ............... $\underline{38}$

D.2. PageRank creditor and debtor centrality measures for selected countries in each layer over time . . . . . . . . . . . . . . . . . . $\ldots$

Tables

1. Distance and Reciprocity Measures for 2009 and 2015 Networks . . . . . . . . . . 9

2. Clustering and Weighted Measures for 2009 and 2015 Networks . . . . . . . . . . 10

3. Centrality Measures for Aggregated and Multiplex Networks in 2015 . . . . . . . 12

4. Countries Exposed to and Affected by the UK Shock in 2015 . . . . . . . . . . . . 18

A.1. Countries and economies exposed to and affected by China shock in 2015 . . . . $\underline{31}$

D.1.1Hubs and authorities centrality measures . . . . . . . . . . 
Figures

1. Global Financial Network Map . . . . . . . . . . . . . . . . . . . 13

2. Creditor Centralities and Banking Assets . . . . . . . . . . . . . . . . . . . . . . . . .

3. Debtor Centralities and Capital Flows . . . . . . . . . . . . . . . . 15

4. Comparison of Shock Propagation in a Multiplex versus Aggregated Networks in

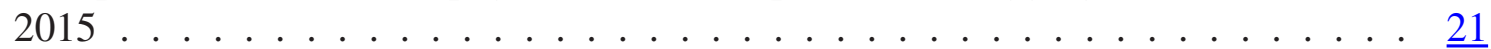

5. Comparison of Shock Propagation in a Multiplex Network in 2009 versus 2015 . . 22

6. Summary of the Contagion Dynamics in the Networks in 2015 . . . . . . . . . 25

7. Schematic Representation of a Multiplex and Aggregated Networks of the Global Financial System . . . . . . . . . . . . . . . . . . . . . . . . . . . . . . . . .

8. Creditor PageRank Score . . . . . . . . . . . . . . . . . 39

9. Debtor PageRank Score . . . . . . . . . . . . . . . . . . . . . . 39

10. Creditor PageRank Score Excluding USA and UK . . . . . . . . . . . . . . . . . . . . . . .

11. Debtor PageRank Score Excluding USA and UK . . . . . . . . . . . . . . . . 40 


\section{INTRODUCTION}

Since the mid-1990s there has been a rapid expansion of cross-border financial positions: the stocks of foreign assets and foreign liabilities have increased to about 172-189 percent of world GDP by 2016 (from about 75-77 percent of world GDP in 1995) and the composition of international balance sheets has evolved substantially. ${ }^{1}$ The share of banking sector positions and portfolio investments increased significantly prior to the GFC, while the share of foreign direct investments (FDIs) in total financing of countries decreased. Rising crossborder financial exposures delivered well-known economic benefits, such as access to new markets, cheaper funding, risk-sharing, and more efficient allocation of capital for many countries $^{2}$, simultaneously led to increased external vulnerabilities in countries that disproportionally relied on foreign inflows as a source for growth. ${ }^{3}$

As discussed in the literature, the size and the composition of the international financial positions can matter for the external adjustment and shock transmission. Countries with larger external vulnerabilities would be under greater pressure to adjust while facing a shock. The financial interlinkages and balance sheet information provides important transmission mechanism by which international shocks affect the value of total (domestic and foreign) financial assets and liabilities, through shifts in global funding and liquidity (Lane, 2015).

This paper contributes to the literature on financial interconnectedness and the global transmission of shocks. We document the evolution of the international financial positions using data on countries' bilateral gross financial asset and liability positions between 2009 and 2015, and discuss a few stylized facts for global financial networks. Second, we simulate international shock transmission in the global financial networks in 2009 and 2015, and conduct comparative analysis.

\footnotetext{
${ }^{1}$ See Lane and Milesi-Ferretti (2017) and WEO (2014) for detailed discussion of the evolution of the crossborder asset and liability positions since 2000 .

${ }^{2}$ See Faria and others (2007), Dell'Ariccia and others (2008), Artis and Hoffmann (2006, 2009), Aghion and others (2010), and Aoki and others (2010).

${ }^{3}$ See for example, Kok and Montagna (2013); Kose, Prasad, and Terrones (2009), Blanchard and others (2016), Neagu and Mihai (2013), Carvalho (2014), Hoggarth, Jung, and Reinhardt (2016). Ghosh, Ostry, and Qureshi (2016) also showed that high capital flows openness can act as a source of risk, when large swings in capital flows can cause financial instability with inflows contributing to unsustainable domestic credit booms and capital stops causing potentially liquidity and funding crises and associated large falls in output.
} 
We use a multilayer network framework ${ }^{4}$ for conducting the analysis which enables us to study shock propagation in the global financial network. An emerging strand of literature uses the multilayer network framework to study the complex nature of systemic risk and financial contagion in the banking systems at a country/regional level as well as between different financial assets (see for example, Caccioli and others (2014), Greenwood, Landier, and Thesmar (2015), Poledna and others (2015), Brummitt, Lee, and Goh (2012) and Bargigli and others (2015)). However, to the best of our knowledge, the use of the multilayer network framework to examine global financial shocks propagation, using countries' bilateral financial positions data split by instrument, has not yet been explored. A multilayer network framework allows an improved identification of shocks' propagation and amplification, as compared to an aggregated or monolayer network approach. ${ }^{5}$

Motivated by this gap in the literature, the main aim of this paper is to simulate contagions in the aggregated network of countries' bilateral financial exposures and to compare simulations' results to a multiplex network in 2009 and in 2015. To explore this question, we rely on volume-based network measures, derived from bilateral financial positions data collected by the IMF and the Bank of International Settlements (BIS). ${ }^{6}$ In total, we work with five network layers consisting of bilateral foreign direct investment positions in debt and equity, portfolio investments in debt and equity, and banking sector loans and deposits. We show that the extent of contagion is larger and spreads faster in our multiplex network. Ignoring the multiplex nature of financial linkages can lead to a biased assessment of the extent and identities of countries impacted by an international financial shock contagion. ${ }^{7}$

The paper proceeds as follows. Section II provides a brief overview of the literature on financial shock contagions and shock transmissions in multilayer networks. Section III discusses a

\footnotetext{
${ }^{4}$ We will use multiplex networks in this research that are a special case of a multilayer networks in which each edge is categorized by its type and interlayer edges only exist between nodes with the same index. Details are provided in the following sections and Appendix.

${ }^{5}$ For example, it was shown that systemic risk in the Mexican banking system between 2007 and 2013 is underestimated by 90 percent when the focus is on a single exposure network rather than multilayered exposure networks Poledna and others (2015). Work by Leon and Renneboog (2014) showed that systemic risk is much higher than those of individual financial networks for Colombian financial institutions and financial market infrastructure networks due to consideration of cross-system risks.

${ }^{6}$ We use the IMF surveys of bilateral international financial positions in debt and equity and BIS banking statistics.

${ }^{7}$ It is important to note that in the current version of the model we do not consider any policy buffers. This paper is intended to provide comparative analysis of shock propagations in the aggregated versus multiplex networks and provide background for discussions of the appropriate type(s) and size(s) of the buffers.
}

CInternational Monetary Fund. Not for Redistribution 
few structural measures for aggregated and multilayer networks which may influence the contagion process. Section IV describes the spreading process that we used to model the financial contagion. In this section, we also show our simulation results for shocks that originate in the UK, USA, euro area (EA), China and Hong Kong SAR using visualization of network maps and shocks-propagation curves. In section $\mathrm{V}$, we give concluding remarks and discuss possible extensions of our work.

\section{RElated Literature OVERVIEW}

There is already an extensive body of work that uses the aggregated or the monolayer network tools for the analysis of financial systems, shocks and spillovers/contagion (see for example, Allen and Gale (2000), Kiyotaki and Moore (2002), Espinosa-Vega and Solé (2011) and Gai and Kapadia (2010)), including at the international cross-border level (Hale (2012), Hale and others (2016), Minoiu and Reyes (2013), Castrén and Kavonius (2009), Chinazzi and others (2013)) and connecting micro and macrolevel data and analysis (Acemoglu, Ozdaglar, and Tahbaz-Salehi (2015), Carvalho (2014), Gabaix (2011)). Modelling and analyzing the global financial network as a monolayer network is a useful first step, but it can oversimplify the representation of the latent network.

Recent literature on networks considers complex interactions among nodes within a multilayer framework (see for example, Salehi and others (2015), Boccaletti and others (2014)). It has been shown that disregarding the multilayer structure can lead to miscalculating or overlooking important system properties. The speed at which information travels - which in our case represents financial shocks - is also affected by network structure and spectral properties (Kivelä and others (2014), DeFord and Pauls (2015)). Nevertheless, there are very few papers yet that use multiplex network tools to assess financial contagion, among them Aoki and others (2010), Poledna and others (2015), Brummitt and Kobayashi (2015), Bargigli and others (2015), Greenwood, Landier, and Thesmar (2015). Most of the existing research looks at microlevel data (for example, banks), and a certain financial instrument (for example, interbank lending) to assess risks to individual country financial stability coming from a failure of an individual institution, a certain instrument type, or a specific type of networks (for example, such as Erdos-Renyi). These papers have shown that multiplex networks are generically more vulnerable to global cascades than simple networks (Brummitt, Lee, and Goh, 2012), and also exhibit non-linearity properties (Poledna and others, 2015). To the best of our knowledge, no study has explored an international financial contagion in a multilayer network framework using data on countries' bilateral financial positions by instrument. 
In terms of data used for the analysis, our work is closely related to those of Kubelec and Sa (2010) and Milesi-Ferretti and Tille (2011). The former examined stocks of bilateral ex-ternal asset and liability positions for a group of 18 countries over the period of 1980-2005, and demonstrated that there has been a significant increase in interconnectivity over the past two decades, with larger and more frequent financial links and a higher degree of openness of countries in the sample. Additionally, the authors found that the network exhibits 'smallworld' properties, such as high clustering and low mean geodesic distances between nodes. The authors claim that the combination of high interconnectivity, a small number of hubs, and 'small-world' properties makes for a robust-yet-fragile system, in which shocks to the key hubs would be rapidly and widely transmitted. Milesi-Ferretti and Tille (2011) used a dataset of bilateral gross and net external positions that covers 70 countries ( 97 percent of global assets) split by instrument. They analyzed gross versus net external positions and identified several stylized facts that emphasize the importance of looking at gross exposures; the importance of the composition of cross-border holdings and sectoral exposures. In this research, we go beyond the initial analysis of Kubelec and Sa (2010) and model the structure of global financial positions using a multilayer framework, taking into consideration composition of cross-border holdings (as emphasized by Milesi-Ferretti and Tille (2011)). We also analyze properties of a global financial multilayer network and their impact on shock propagation.

Network tools allow the modelling of financial shocks transmission through direct and indirect financial linkages between countries (Cabrales, Gale, and Gottardi, 2015). Usually, the manner in which the shock affects other institutions/countries is a decrease in the value of assets of said institution/country in response to the shock. If the value of an institution's assets after shock is significantly lower (below a certain threshold) than its liabilities the institution needs to adjust its liabilities (including to other institutions) and in this way the shock propagates through the network. ${ }^{8}$ This type of models for financial contagion have been extensively explored for different type of financial linkages (see for example, Acemoglu, Ozdaglar, and Tahbaz-Salehi (2015), Elliott, Golub, and Jackson (2014) and Glasserman and Young (2015)). The issue of contagion for large random or non-symmetric networks is usually approached in a numerical form (Cabrales, Gale, and Gottardi, 2015). For example, the Watts threshold model has been extended to model financial contagion on networks with different degree distribution and results show that connectivity plays an important role (Gai and Kapadia, 2010). Threshold models have also been used to define centrality measures for large, non-symmetric financial networks. For example, a three-state threshold model was used to compute Deb-

\footnotetext{
${ }^{8}$ In other words, if the assets lost due to a shock is above a certain threshold the institution could default on it's liabilities (domestic or foreign).
}

CInternational Monetary Fund. Not for Redistribution 
tRank, which ranks nodes by the fraction of total economic value that is potentially affected by the distress or the default of a node (Battiston and others, 2012). In this paper, we focus on large and non-symmetric networks, therefore we use a simulation approach, where we extend threshold models of financial contagion to a multiplex framework.

\section{Descriptive Analysis of the Global Financial Network}

\section{A. Data for Networks}

Our research uses the detailed resident based IMF Coordinated Direct Investments Survey (CDIS), IMF Coordinated Portfolio Investment Survey (CPIS), and the BIS International Banking Statistics for the period 2008-2015. The data have an annual frequency and there are 230 countries and self-governed territories and jurisdictions in the database. To map country bilateral positions' data into the global bilateral financial position networks, we used the conceptual framework provided by the IMF Global Financial Flows of Funds approach (for details, see Errico and others (2014)). Missing data and data gaps were filled either by using mirror statistics or national data sources (specifically, Bundesbank and USTIC database). ${ }^{9}$ Using this database, we constructed six networks for each year: (i) bilateral foreign direct investments in equity (FDI-equity); (ii) bilateral foreign direct investments in debt (FDI-debt); (iii) bilateral portfolio investments in equity (PI-equity); (iv) bilateral portfolio investments in debt securities (PI-debt); (v) banks loans and deposits (BLD); and (vi) aggregated network of bilateral international financial positions defined as a sum of the five individual networks. We construct an aggregated and a five-layer multiplex network to simulate financial shock propagation and to compare contagion results between the two for a single period and between periods. Networks are directed and edges are weighted. The convention used for the direction of edges is from B to A if country A has a claim on country B. Details of the coupling, mapping and aggregation of the multiplex network can be found in Annex B.

\footnotetext{
${ }^{9}$ Data availability and gaps, as well as the fit of the data for the analysis of global financial interconnectedness and shock propagations has been discussed in length in Cerutti and Zhou (2017), Kubelec and Sa (2010), MilesiFerretti and Tille (2011), Lane and Milesi-Ferretti (2017). We choose to work with the residence base data to be able to match the BIS banking statistics with the IMF's CDIS and CPIS survey data by country to go beyond the analysis of bank data only.
}

(C)International Monetary Fund. Not for Redistribution 


\section{B. Conjunctural Analysis of Global Financial Network Using Multiplex Networks Tools}

In this section, we analyze the global financial network properties and dynamics by comparing multilayer and aggregated networks over time. For each year and each asset type in the sample, we calculate several basic network statistics (B.1), we then conduct a more detail analysis of important network players using PageRank centrality measures (B.2).

\section{Basic measures of network structure}

For the broad comparison of the global financial network structure we calculate basic structural network measures for 2009 and 2015 years. In Table 1, we summarize structural measures for the unweighted but directed networks. In Table 2, we show structural measures for unweighted and undirected networks. For formal definitions we refer the reader to Newman $(2010)^{10}$, below we present economically intuitive descriptions. In each of the networks, the geodesic distance between two countries is the minimum of the financial claims between countries. The diameter is the largest of these distances. In our networks, the diameter is small compared to the number of nodes. The edge density is the ratio between the bilateral claims (edges) that take place and the total possible claims in the network. Note that if every country invested in all countries, then the values in Table 1 would all equal 1 . In Table 2, we show local (triangular) clustering of our networks. In economic terms, this illustrates the likelihood that two countries that reciprocally invest in each other also invest in the same third countries.

Table 1. Distance and Reciprocity Measures for 2009 and 2015 Networks

\begin{tabular}{|c|c|c|c|c|c|c|c|c|}
\hline \multirow[t]{2}{*}{ Network } & \multicolumn{2}{|c|}{ Diameter } & \multicolumn{2}{|c|}{ Edge Density } & \multicolumn{2}{|c|}{ Mean Geodesic Distance } & \multicolumn{2}{|c|}{ Reciprocity } \\
\hline & 2009 & 2015 & 2009 & 2015 & 2009 & 2015 & 2009 & 2015 \\
\hline FDI equity & 4 & 3 & 0.13 & 0.16 & 1.94 & 1.87 & 0.58 & 0.56 \\
\hline FDI debt & 4 & 4 & 0.11 & 0.15 & 2.05 & 1.92 & 0.76 & 0.76 \\
\hline PI equity & 4 & 4 & 0.10 & 0.11 & 2.19 & 2.13 & 0.54 & 0.53 \\
\hline PI debt & 4 & 4 & 0.10 & 0.12 & 2.1 & 2.06 & 0.56 & 0.5 \\
\hline BLD & 3 & 3 & 0.14 & 0.19 & 1.85 & 1.79 & 0.82 & 0.83 \\
\hline Aggregated & 3 & 3 & 0.25 & 0.31 & 1.75 & 1.68 & 0.76 & 0.78 \\
\hline
\end{tabular}

Source: IMF, BIS, authors' calculations. The table shows distance and reciprocity measures for the unweighted and directed networks.

\footnotetext{
${ }^{10} \mathrm{We}$ clarify that by global clustering coefficient we refer to the fraction closed triples and by reciprocity we refer to the frequency of loops of length two.
} 
Table 2. Clustering and Weighted Measures for 2009 and 2015 Networks

\begin{tabular}{|c|c|c|c|c|c|c|}
\hline \multirow[t]{2}{*}{ Network } & \multicolumn{2}{|c|}{ Global clustering coefficient } & \multicolumn{2}{|c|}{ Mean local clustering coefficient } & \multicolumn{2}{|c|}{ Sum of weights } \\
\hline & 2009 & 2015 & 2009 & 2015 & 2009 & 2015 \\
\hline FDI equity & 0.48 & 0.48 & 0.48 & 0.47 & 19353339 & 28911499 \\
\hline FDI debt & 0.50 & 0.49 & 0.32 & 0.38 & 7706659 & 9309917 \\
\hline PI equity & 0.57 & 0.57 & 0.62 & 0.61 & 13770285 & 22017199 \\
\hline PI debt & 0.57 & 0.57 & 0.58 & 0.58 & 21192710 & 21598862 \\
\hline BLD & 0.36 & 0.38 & 0.34 & 0.31 & 22061901 & 18592051 \\
\hline Aggregated & 0.57 & 0.59 & 0.39 & 0.36 & 84084894 & 100429528 \\
\hline
\end{tabular}

Source: IMF, BIS, authors' calculations. The table shows clustering and weighting measures for the unweighted and undirected networks.

The initial comparison of global financial network structural measures illustrates the similarity of the aggregated networks in 2009 and 2015. The temporal differences between different types of financial layers are also modest. The FDI equity and debt layers (including intercompany debt lending) have changed the most. The network of FDI bilateral positions has grown - our calculations suggest that there has been a significant expansion of borrowing in volume terms and a larger number of market participants (countries) started lending using these types of instruments. This result revealed by the network means geodesic distance decrease (for FDI equity network the diameter decreased as well) and increase in edge density of the network ${ }^{11,12}$. One potential explanation of this change is the replacement of banking funding by European banks after the GFC with equity and debt borrowing, as noticed by Chung and Shin (2014) and Turner (2014).

\section{PageRank centrality}

There is no widely accepted methodology to determine the systemically important nodes in a network. The network structural measure we use in this paper for the analysis of shock propagation is the PageRank centrality measure (for aggregated and multiplex networks). PageRank centrality measure is used in finance literature to determine systemically important financial institutions for financial stability (Kaltwasser and Spelta, 2012); in trade literature to

\footnotetext{
${ }^{11}$ It is important to note that structural measures are indifferent to node labels, so if two countries switch roles over time, structural measures will not show any change. This could help provide a partial explanation of the low variation in the global financial network over time.

${ }^{12}$ Calculating measures of network structure for the multiplex network is time consuming, and, as it is not the main purpose of this research, we decided to leave it out for future research.
} 
analyze trade dynamics and value chains (Benedictis and Vicarelli, 2014); and to determine key industries in world input-output tables (Cerina and Riccaboni, 2014). We use PageR-ank centrality measure for the analysis of central countries in the global financial networks of borrowers and lenders, which reflects the relative importance of a country in the global financial network, taking into account the size of its financial activity (total claims or liabilities), the number of financial partners, and the importance of these partners in the overall financial network. ${ }^{13}$ PageRank centrality measure takes into consideration the direction of linkages, ranking higher countries which are more accessible and therefore countries with higher indegree are ranked higher. We use two measures of PageRank centrality for the analysis of countries that are major lenders and borrowers in the global financial network: creditor PageRank centrality measure with direction of edges from debtor to creditor, and debtor PageRank centrality measure by inverting the direction of the edges. ${ }^{14}$ Table 3 compares PageRank centrality measures for aggregated and multilayer networks in 2015 for gross bilateral assets (creditor) and liabilities (debtor) positions.

Table 3 shows that a very similar set of countries were ranked as the top ten most central countries in the global financial network in 2015 on both aggregated and multiplex networks (using either bilateral assets (creditor PageRank) or liabilities (debtor PageRank) positions). However, there is more variation in the ranking of the 20 central countries. Large emerging market economies (India, Brazil, and Mexico) were ranked among top twenty countries using multiplex debtor PageRank centrality measure, while Mauritius, South Korea, and Kuwait ranked high in terms of their lending in 2015 (based on creditor PageRank centrality). The Cayman Islands and Ireland, despite being ranked relatively high in the aggregated network (on both debtor and creditor PageRank centrality measures), ranked lower in the multiplex network. They dropped out from top twenty major creditors on multiplex network, possibly due to asymmetric importance of Cayman Islands for the USA banks and Ireland's financial institutions for the USA and large European financial centers.

\footnotetext{
${ }^{13}$ The PageRank centrality of a node i corresponds to the probability of being at the node in the steady state of a teleporting random walk. See Annex B for further details on this measure.

${ }^{14}$ To check robustness of our results to the use of other network measures with similar properties, we calculated Hubs (for debtors) and Authorities (for creditors) measures for aggregated and multiplex networks. The results are very similar for top ten countries and economies (see Table 1 in Annex D.1), however, Japan and Hong Kong SAR are rated higher on multiplex authority measure - fourth and seventh the most important creditors in the network, while China ranked significantly lower (number 16) on multiplex Hubs measure, relative to multiplex debtor PageRank centrality measure.
}

CInternational Monetary Fund. Not for Redistribution 
Table 3. Centrality Measures for Aggregated and Multiplex Networks in 2015

\begin{tabular}{|c|c|c|c|c|}
\hline Rank & $\begin{array}{l}\text { PageRank } \\
\text { (creditor) Aggre- } \\
\text { gated network }\end{array}$ & $\begin{array}{l}\text { PageRank } \\
\text { (debtor) Aggre- } \\
\text { gated network }\end{array}$ & $\begin{array}{l}\text { PageRank } \\
\text { (creditor) Multi- } \\
\text { plex network }\end{array}$ & $\begin{array}{l}\text { PageRank } \\
\text { (debtor) Mul- } \\
\text { tiplex network }\end{array}$ \\
\hline 1 & United States & United States & United States & United States \\
\hline 2 & United Kingdom & United Kingdom & Luxembourg & United Kingdom \\
\hline 3 & Luxembourg & Luxembourg & United Kingdom & France \\
\hline 4 & Netherlands & Netherlands & Netherlands & Luxembourg \\
\hline 5 & France & France & France & Netherlands \\
\hline 6 & Germany & Germany & Germany & Cayman Islands \\
\hline 7 & Japan & Cayman Islands & Japan & Germany \\
\hline 8 & $\begin{array}{l}\text { Hong Kong } \\
\text { SAR }\end{array}$ & Switzerland & Switzerland & Ireland \\
\hline 9 & Switzerland & Ireland & $\begin{array}{l}\text { Hong Kong } \\
\text { SAR }\end{array}$ & China \\
\hline 10 & China & Japan & Italy & Switzerland \\
\hline 11 & Italy & $\begin{array}{l}\text { Hong Kong } \\
\text { SAR }\end{array}$ & Belgium & India \\
\hline 12 & Canada & China & Mauritius & Japan \\
\hline 13 & Belgium & Canada & South Korea & Australia \\
\hline 14 & Ireland & Italy & Singapore & Brazil \\
\hline 15 & Cayman Islands & Spain & Canada & $\begin{array}{l}\text { Hong Kong } \\
\text { SAR }\end{array}$ \\
\hline 16 & Spain & Australia & China & Spain \\
\hline 17 & Sweden & Belgium & Kuwait & Italy \\
\hline 18 & Singapore & Singapore & Sweden & Canada \\
\hline 19 & Norway & India & Denmark & Mexico \\
\hline 20 & Bermuda & Bermuda & Norway & Belgium \\
\hline
\end{tabular}

Source: IMF, BIS, authors' calculations.

To illustrate the main developments over time, we compare centrality measures for 2009 and 2015 for a multiplex network for a sample of approximately fifty most important countries in the network (see Figure 1).

The USA remains the most influential country in the global financial network in terms of the size of its gross assets/liabilities and close links to other influential countries in the network. Importantly, after the GFC, the USA financial institutions increased their cross-border assets and liabilities, shown in Figure 1 with much thicker arrows between the USA and the UK, Japan, Luxembourg, and China in 2015 relative to 2009. The UK, despite remaining the sec- 


\section{Figure 1. Global Financial Network Map}

(a) Global Financial Network 2009

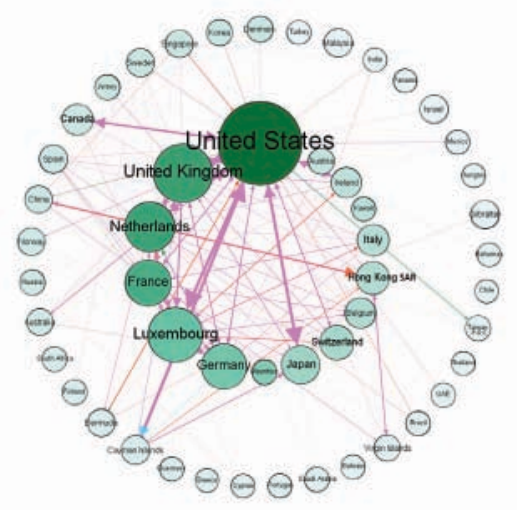

(b) Global Financial Network 2015

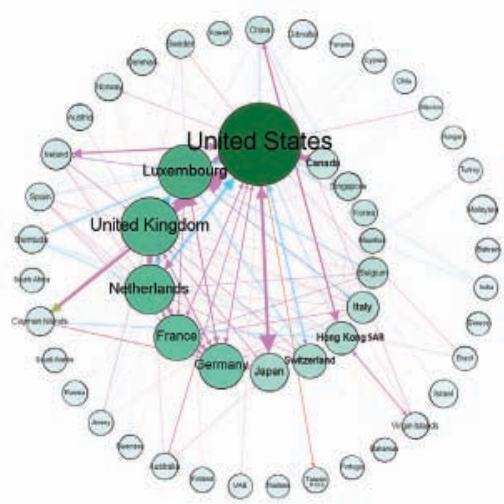

Source: IMF, BIS, authors' calculations. The node size and color intensity is determined by its PageRank centrality; edge width is defined based on total bilateral claims; the edge color represents the major portion (75\%) of total claims (in green for banking; blue for equity; red for debt; and pink for mixed claims' edges (with share of banking, equity, or debt instruments in the total bilateral claims less than $75 \%$ ).

ond (as a debtor) and third (as a creditor) most central country in the network, has decreased it centrality in 2015 relative to 2009, as UK financial institutions continued to adjust their balance sheets after the GFC and during the European banking crisis. France moved down a notch from the fourth place in 2009 to being the fifth most central country in the network in 2015 possibly for the same reason. The phenomenon of increased size investment fund industry made Luxembourg more central in the network, as it became a central debt and equity hub in Europe in 2015, intermediating funds between Europe and the USA. Another significant change in the network in 2015 is an increased centrality of China in the global financial network. China moved eight positions up as a creditor and became sixteenth largest lender in the global financial network; and moved three position up as a central debtor country, which made China ninth most influential borrower in the global financial network in 2015. This could be due to the increasing financial ties between China and Hong Kong SAR, and the USA (primarily driven by the increased bilateral securities positions). Another important observation is that large Asian countries and economies like China, Japan, Hong Kong SAR, Singapore, and South Korea have increased its centrality in the global financial network in 2015 relative to 2009 . Finally, Canada moved from the outer circle into the inner circle on Figure 1, taking the fifteenth position in the ranking of the most central creditor countries in global financial network. This move can be explained by the increased lending to the USA.

More generally, when comparing the 2009 and 2015 networks (Figure 1), we can see that the network edges (financial linkages) become more diversified between countries in 2015, relative to a high reliance on solely debt and banking funding in 2009 (more green and red arrows 
in the depicted network in 2009). In 2015, we see an emergence of bilateral equity flows (in blue), for example, connecting USA to Netherlands and Switzerland. Another development is that the ties (arrow thickness) became more pronounced between some very central countries, such as the USA and China, the USA and Luxembourg, and the USA and Canada.

Another way to illustrate key developments in the global financial network is to calculate changes in creditor and debtor PageRank centrality measures between 2009 and 2015 (see Figure 2a). First, using changes in creditor PageRank centrality, we can show that most European countries (with few exceptions, notably of Luxembourg and Germany) decreased their centrality in the network as lenders post GFC, which can be explained by European banking system deleveraging (Figure 2b). ${ }^{15}$ Luxembourg, the USA, and Germany are the top three countries that have the highest increase in their creditor PageRank centrality in 2015 relative to 2009. Luxembourg saw the largest changes to its creditor centrality in the network after the GFC. Luxembourg has one of the largest investment fund and wealth-management industries in Europe, and it hosts many foreign banks subsidiaries, which aggregate liquidity from investment fund and wealth-management operations and "upsteam" it to their "parents" abroad. As shown in Figure 1, many European countries significantly increased their equity positions on Luxembourg in 2015, while Luxembourg grew its exposure on the USA.

Second, we can also analyze changes in debtors' PageRank centrality measure. After the GFC, the role of emerging markets (EMs) as cross-border borrowers increased. Half of the global inflows after the crisis was to EMs, compared to less than 20 percent before the GFC (see Figure 3a). The change in debtors' PageRank centrality measure suggests that many Asian countries and economies (including China, Hong Kong SAR, and Japan) and large EMs (Brazil, India) has significantly increased their centrality in the network as major borrowers, while European countries decreased their importance (Figure 3b).

\footnotetext{
${ }^{15}$ The persistent aggregate decline in cross-border banking claims of European banks has been discussed in Lund and others (2013), Forbes (2014), Forbes, Reinhardt, and Wieladek (2017), Lane and Milesi-Ferretti (2017), and Mallaby (2016).
} 
Figure 2. Creditor Centralities and Banking Assets

(a) Change in multilayer creditor PageRank centrality between 2009 and 2015

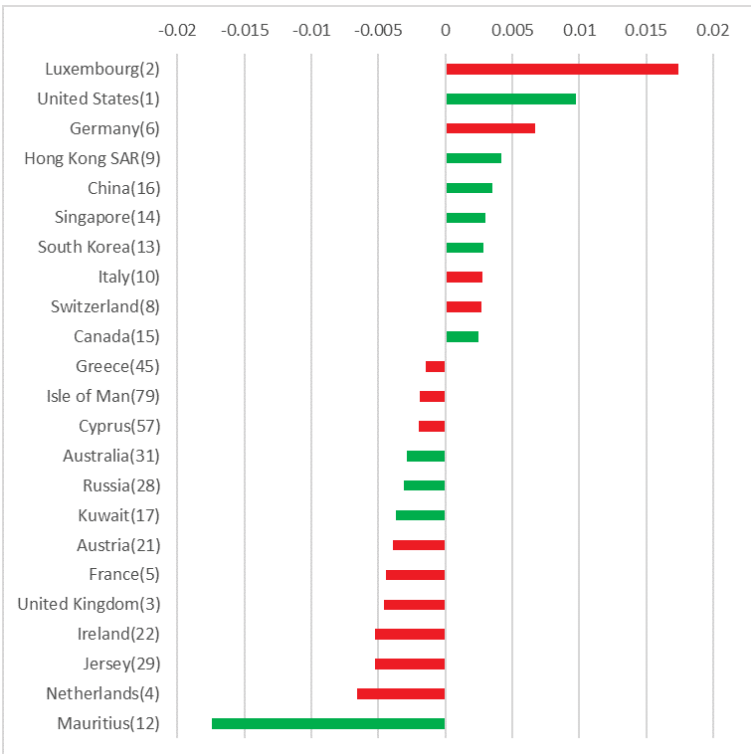

(b) Change in banking sector assets versus change in centrality

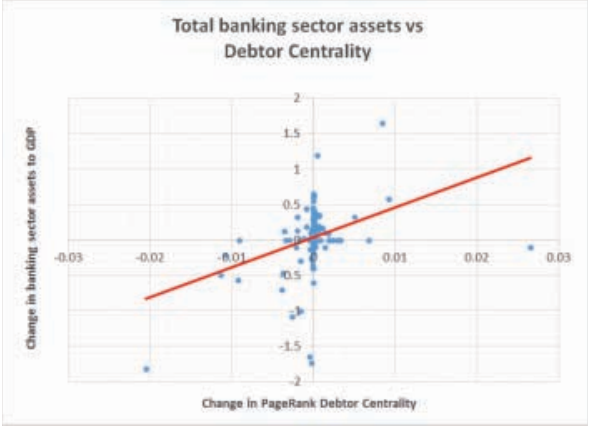

Source: IMF, BIS, authors' calculations. Bars in red represent European countries. Numbers in parentheses are the ranking of the countries according to the creditor PageRank centrality in 2015.

Figure 3. Debtor Centralities and Capital Flows

(a) Change in multilayer debtor PageRank centrality between 2009 and 2015

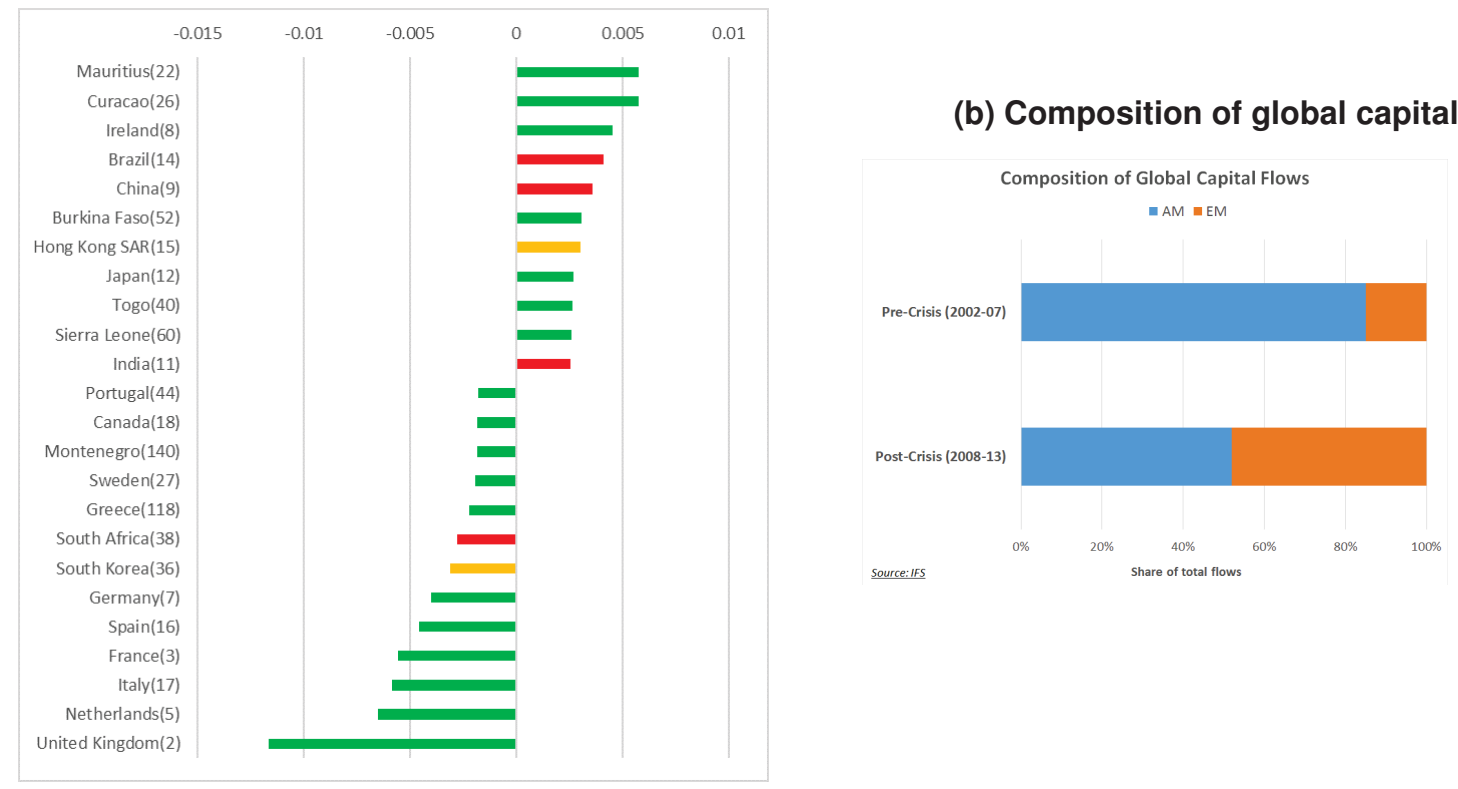

Source: IMF, BIS, IFS, authors' calculations. Bars in red represent G-20 EMs, bars in yellow other Emerging Asian countries. Numbers in parentheses are the ranking of the countries according to the debtor PageRank centrality in 2015. 


\section{Contagion: Methodology and Results}

\section{A. Threshold Contagion Model: Methodology}

As described in the introduction and the data section, due to the different nature - and therefore interaction - of financial cross-border positions (equity versus debt versus bank funding) we use a multiplex network model where nodes represent countries, edges financial obligations and layers specify the type of obligations (direct investment in debt, portfolio investment in equity, etc). The edges are directed from the debtor to the creditor country. Furthermore, each country is present in each of the five layers and interlayer edges are only between the same country.

Our approach to model contagion is inspired by the literature on financial contagion using threshold models mentioned in section II. Generally, these models assume a binary state for a node (for example, in epidemiology it would be either healthy or infected)- and at each time step a node may switch from being healthy to inflected if a fraction of infected neighboring nodes is above a specific threshold. In our model, each node/country in each layer (for each financial instrument) is assigned a state either "healthy" or "defaulted". A node will only change its state from healthy to defaulted if the contagion rule is satisfied. Once the country is assigned a state "defaulted" it will remain "defaulted" for the rest of the simulation. The initialization of the simulation is done by setting, at time zero, all nodes except one - which we refer to as the country that experienced a shock-to state "healthy" while the country that experienced a shock is set to "defaulted." In the following time steps the state of a node will change from "healthy" to "defaulted" only if either of the following conditions are satisfied: (1) the borrower of a country that experienced a shock in another layer has defaulted; and/or (2) the fraction of incoming links' weights that come from a defaulted neighbor is above a predetermined threshold. The threshold is the same for all nodes. We stop the simulation once no node changes its state. At the end of the simulation we count the number of defaulted countries, this depends on the country that experienced a shock and on the threshold. The model for contagion on the aggregated network is like the one outlined above, with one difference that the change of state only comes from satisfying the condition 2 outlined above. Further details of threshold models can be found in Annex B.

The model is discrete, deterministic and reaches a steady state in a finite number of time steps. Intralayer contagion occurs when a node changes its state from "healthy" to "defaulted" when the fraction of incoming links from defaulted neighbors is above a certain threshold while 
interlayer contagion is imminent between two connected nodes if one has defaulted (this is by design and will need to be changed in the following version of the model). The results of the model are obtained by simulation. We compare the results of the multiplex contagion model with a threshold model on an aggregated (monolayer) network obtained by aggregation of all layers.

\section{B. Contagion in the Global Ffinancial Network: Simulation Results}

We use the 2015 multilayer global financial network to simulate shock propagations.

We consider standard channels of financial contagion discussed in the literature - credit risk or liquidity risk (Allen and Gale, 2000). For example, a shock to the value of country B's banks assets can cause a drop in the value of real estate or growth shock in an industrial sector to which country B's banks have an exposure. Such a drop in the value of assets is initially absorbed by country B bank's net worth. However, if the shock is above a certain threshold, the net worth can be wiped out, and the bank then is unable to fully repay its obligations, so it defaults. Thus, country B's actual payments to banks in country A will be less than their contract value. If the payment shortfall is sufficiently large, it can push banks in country A to default as well, and so on. An initial asset shock to a bank in one country B can spillover to other banks inside and potentially outside country B, creating a cascade of defaults and contagion. Another type of contagion arises when banks pull funding from one another liquidity or funding shock. Such a funding run can be triggered by an unexpected liquidity shock, as described in Dimond and Dybvig (1983), and the literature builds and extends their framework. Thus, banks will reduce their lending to adjust to a shock. ${ }^{16,17}$ Currently, we do not distinguish between the types and magnitude of the shocks, and we take as given the thresholds for intra- and interlayer contagions. Further work is needed to model contagion thresholds, as they can also vary by country and instrument.

As an example, we demonstrate simulation results for a shock that hits the UK financial system and propagates to other countries in the global financial network through their claims on the UK. In the case of the UK, at step 1 we assume that the UK resident banks are hit by a

\footnotetext{
$\overline{{ }^{16}}$ The relevant literature is large. See, for example, Allen and Gale (2000), Gai and Kapadia (2010), etc.

${ }^{17}$ Another possibility for a contagion is through common exposures, which may be subject to correlated shocks and trigger fire sales. See for example, Bluhm (2013), Greenwood, Landier, and Thesmar (2015), Caccioli and others (2014).
}

(C)International Monetary Fund. Not for Redistribution 
Table 4. Countries Exposed to and Affected by the UK Shock in 2015.

\begin{tabular}{|c|c|c|c|}
\hline & \multirow[b]{2}{*}{ Country } & \multicolumn{2}{|c|}{ Proportion of the UK in: } \\
\hline & & Total claims & Banks' claims \\
\hline 1 & Sierra Leone & $78 \%$ & $82 \%$ \\
\hline 2 & Isle of Man & $77 \%$ & $73 \%$ \\
\hline 3 & US Pacific Islands & $64 \%$ & $79 \%$ \\
\hline 4 & Malawi & $45 \%$ & $54 \%$ \\
\hline 5 & Jersey & $39 \%$ & $70 \%$ \\
\hline 6 & Nigeria & $38 \%$ & $54 \%$ \\
\hline 7 & Kyrgyz Republic & $38 \%$ & $41 \%$ \\
\hline 8 & Bangladesh & $36 \%$ & $51 \%$ \\
\hline 9 & Zambia & $36 \%$ & $42 \%$ \\
\hline 10 & Ghana & $35 \%$ & $51 \%$ \\
\hline 11 & Libya & $32 \%$ & $36 \%$ \\
\hline 12 & Gabon & $32 \%$ & $50 \%$ \\
\hline 13 & Gambia & $32 \%$ & $39 \%$ \\
\hline 14 & Kenya & $32 \%$ & $40 \%$ \\
\hline 15 & Afghanistan & $30 \%$ & $60 \%$ \\
\hline 16 & Uganda & $29 \%$ & $46 \%$ \\
\hline 17 & Iceland & $27 \%$ & $78 \%$ \\
\hline 18 & Rwanda & $27 \%$ & $49 \%$ \\
\hline 19 & Qatar & $27 \%$ & $54 \%$ \\
\hline 20 & Guernsey & $26 \%$ & $37 \%$ \\
\hline 21 & Saudi Arabia & $26 \%$ & $46 \%$ \\
\hline 22 & St. Lucia & $25 \%$ & $35 \%$ \\
\hline 23 & Greece & $20 \%$ & $55 \%$ \\
\hline 24 & Kazakhstan & $15 \%$ & $51 \%$ \\
\hline 25 & Norway & $11 \%$ & $38 \%$ \\
\hline 26 & Ireland & $10 \%$ & $41 \%$ \\
\hline 27 & Slovak Republic & $9 \%$ & $36 \%$ \\
\hline 28 & Poland & $8 \%$ & $37 \%$ \\
\hline
\end{tabular}

Source: IMF, BIS, authors' calculations. The table shows the percentage of country's total claims and total banks' claims in the UK. Numbers shown in red are for countries with total claims above the 35 percent threshold that would be in financial distress.

credit risk shock, as described above, to their assets and thus need to adjust the liability side of the balance sheets. ${ }^{18}$ The UK cuts its exposures (i.e. deleverages) to its creditor countries. The direct impact of the shock - i.e. countries affected in time step 2 - depends on the extent

${ }^{18}$ In this paper, we abstain from the discussion of the sources of shocks and their magnitudes. Nevertheless, to put our simulations in perspective, the size of our simulated shock is slightly smaller in magnitude to the shock affecting countries during 2008-09 GFC. 
of a creditor's UK banking system exposure. In this example, we assume a threshold of 35 percent, - i.e., a share of UK banking financial assets in countries' cross-border portfolio of equal to or above 35 percent. In 2015, a total of 28 countries, including Saudi Arabia (a G-20 country), in the network had more than 35 percent UK banking system assets in their portfolios (see second column in Table 4). This is a set of countries that is affected first, with 35 percent of their cross-border banking claims being wiped out. It is important to emphasize that the multilayer structure of the network allows us to identify these 28 countries with large banking claims on the UK. If we were simulating similar shock contagion using aggregated network (or sum of the total claims), only 9 of these 28 countries would have more than 35 percent of assets in the UK (see first column in Table 4), and, therefore, would be directly impacted by this shock.

In the next step of the multiplex contagion simulation, a larger set of countries is going to be affected, as indirect linkages to the UK are taken into consideration. This implies that at this step, countries whose joint exposure to the UK, Greece, Saudi Arabia, Ireland, and Poland and other countries in Table 4 are in the excess of 35 percent will be affected by the shock. In step nine, all G-20 countries are affected by the shock to the UK banks, through either the banking, debt, or equity layers. The contagion will continue until the entire network is impacted by the shock, and for this example with the UK, it takes 10 steps. Interestingly, a similar type of a shock to the US resident banks with the threshold of 35 percent propagates faster through the network; it takes only eight steps for all countries in the network to be impacted by the comparable USA banking shock. All G-20 are affected at the step number seven. ${ }^{19}$ Also, the updating rule is done for all nodes at the same time, meaning that the model is synchronous. We let the model run until it reaches a steady state, when no node changes its state. In the following section, we focus on the given number of countries which changes their state to "defaulted" in the steady state.

Table 4 gives insights on how multilayer structure can amplify the contagion caused by the UK shock. We can construct similar tables for other seed countries (see for example, Annex A Table 1 for China). In the Annex A Table 1, we show the percentage of assets affected by the shock originating in China in aggregated network in one column and the percentage of assets lost on a specific layer in the multilayer network in another column. This specific layer is the one in which the shock coming from a seed country causes the largest number of

\footnotetext{
${ }^{19}$ As noted earlier, the current model does not consider policy buffers and is intended for comparative analysis of shock propagations in the aggregated versus multiplex networks to provide background for discussions of the policy buffers. Further work is underway to incorporate country/sector specific policy buffers into the multilayer network contagion model.
}

CInternational Monetary Fund. Not for Redistribution 
countries to "default". For the UK, this is the banking layer (BLD); but for other countries, a different layer can play this role. In particular, for China, the most susceptible layer is foreign direct investments in equity (FDI-equity). For China, with a similar threshold of 35 percent, 29 countries are affected in the FDI-equity layer. Majority of the countries are low-income countries in Africa or resource rich countries, targeted by China due to its growing energy need.

\section{Contagion Dynamics in the Global Financial Network}

We now compare the dynamics of shock propagation in the aggregated versus multiples networks. We also consider how shock propagation has changed in the multiplex network over time by comparing contagion results for 2009 and 2015 networks.

In Figure 4, we show shock propagation curves for idiosyncratic shocks that hit countries in the network. Each curve shows what share of the world has been affected by the shock for a different threshold value. The vertical axis shows the number of countries that are affected and the horizontal axis shows the threshold level. The further to the left of the curve, the faster the shock propagates.

Comparing contagion dynamics for aggregated and multiplex networks in 2015, we observe that the results show significant differences in shock propagation for all countries, including for the USA. A larger shock contagion in the multiplex networks might be explained by relatively high PageRank centrality of countries on one or several layers. For example, for the USA and the UK this might be explained by high creditor or debtor PageRank centrality on banking layer. While in case of Luxembourg or Hong Kong SAR, it might be explained by relatively high ranking of Luxembourg on equity and debt layers for creditor PageRank centrality and by high debtor centrality of Hong Kong SAR on foreign direct investments equity layer. Since the GFC, Luxembourg served as a hub in Europe for the USA and the UK resident investment funds', and Hong Kong SAR performed a similar role for the mainland Chinese investors.

Another informative calculation is shock propagation in the multiplex network over time (see Figure 5). In general, the global financial network remained very susceptible (in terms of number of countries affected) to shocks to the USA. As we show in the top left panel of Figure 5 above 50 countries are rapidly affected even with a very low threshold of 0.009 , 
Figure 4. Comparison of Shock Propagation in a Multiplex versus Aggregated Networks in 2015
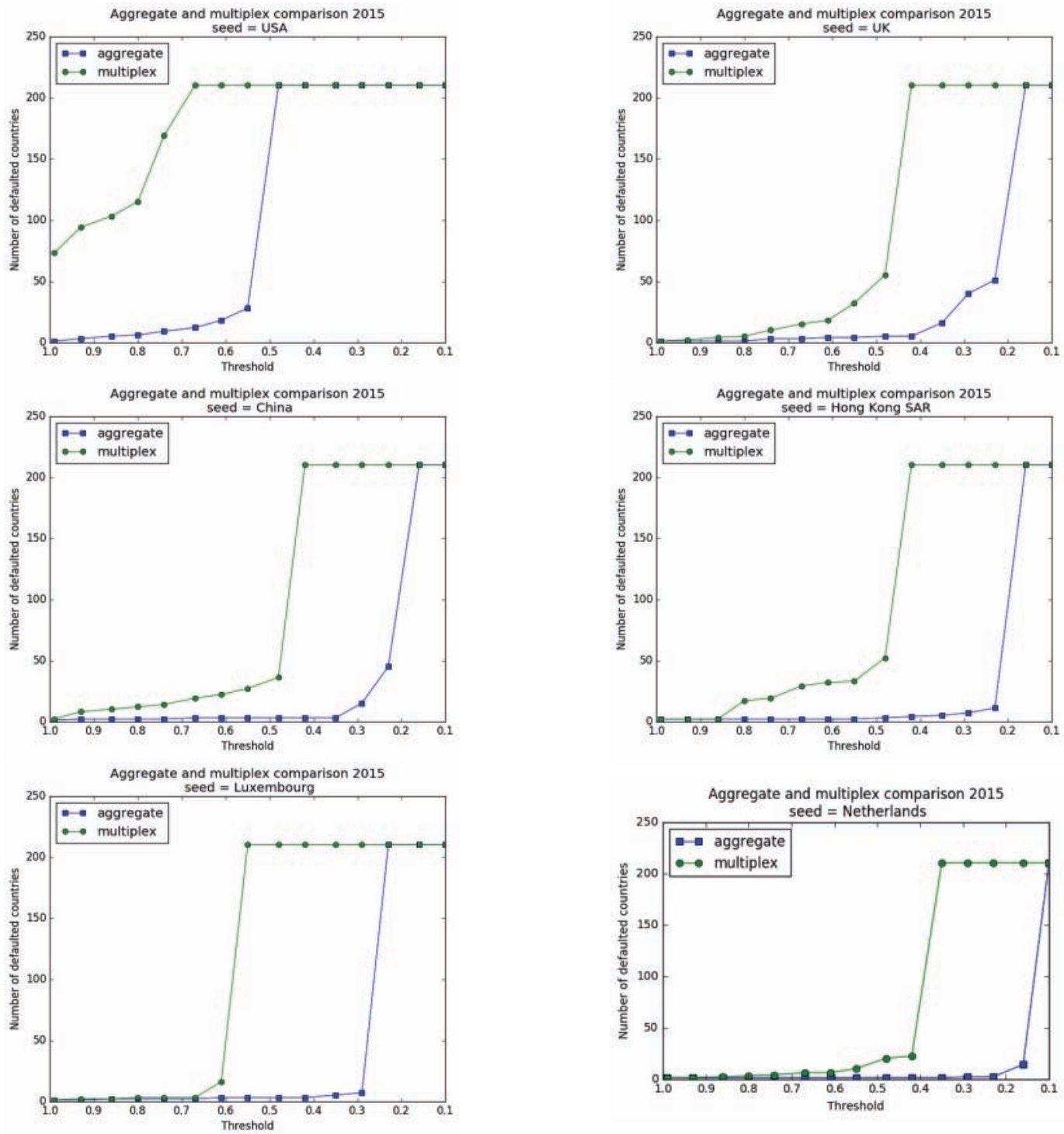

Source: IMF, BIS, authors' calculations. The plots show for a specific seed country the number of affected countries given the threshold used in the simulation. Results show increasing fragility of the system when considering multiple channels of contagion. In these simulations the default of a country in one layer is immediately propagated to the other layers.

as there are a significant number of financially undiversified countries in the network with high reliance on the USA investments/funding. Despite the global systemic importance of the UK banks and the importance of the UK as a financial center in Europe, the network is relatively less susceptible (less countries are impacted at similar threshold level) to the shocks coming from the UK than from the USA, and over time, network fragility to UK shocks has 
Figure 5. Comparison of Shock Propagation in a Multiplex Network in 2009 versus 2015
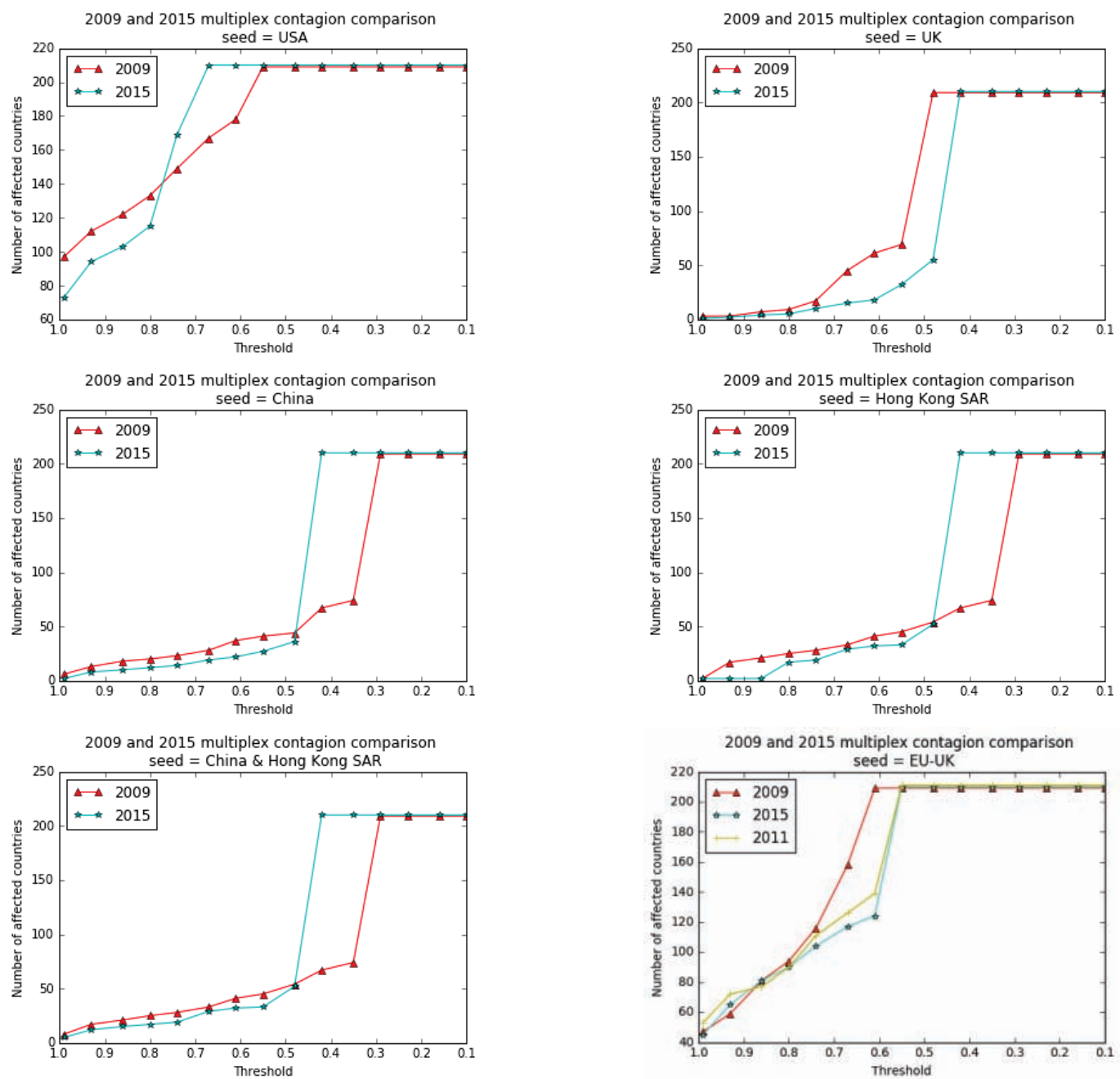

Source: IMF, BIS, authors' calculations. The plots show for a specific seed country the number of affected countries given the threshold used in the simulation. In these simulations, the default of a country in one layer is immediately propagated to the other layers.

decreased, partly as a result of the European bank deleveraging, and possibly partly due to the sell-offs of the safe assets in search for yield under low interest rates environment.

The rising centrality and importance of Asian countries in the network was discussed earlier and the dynamics of the contagion in the multiplex network support it. The network was more susceptible to shocks originating in China and Hong Kong SAR in 2015 than in 2009. When considering a threshold of 35 percent a shock to any of these two countries can be compared to the shock to the UK financial system in terms of the number of countries impacted by the shock (see the bottom left panel of the Figure 5 and Figure 6 bar chart). To asses the sensi- 
tivity of the results to our choice of threshold, we also present the impact of the shock across verifying threshold levels in Figure 6. The contour plots in Figure 6 shows that, as expected, the number of affected countries increase as the shock threshold reduces. In addition, the multiplex model is more susceptible to network shocks, since a larger number of counties are affected at higher thresholds, relative to the aggregated network.

We have also simulated a shock to the euro area (EA) financial system in 2009, 2011, and 2015. Despite low sensitivity of the network to individual European country shocks, a shock to the entire EA financial system makes the network extremely contagious (many more countries are impacted by the shock at the same threshold level). Despite some decrease in network susceptibility to the EA financial shock since 2009, it remains high and is comparable in scale to the USA or the UK shocks (see Figure 5).

\section{Conclusion}

This paper develops new insights into the analysis of the global financial network and the propagation of financial shocks by using a multilayer network framework. Descriptive network statistics, and contagion simulations show that despite significant changes in some types of financing (bank financing versus FDI) for certain regions/countries (Europe versus Asia), the transmission of shocks remains similar in 2009 and 2015 (in terms of number of countries affected). The global financial network remains most susceptible to shocks coming from large central countries (defined as systemic countries in the financial network) and countries with large financial systems (namely, the USA and the UK). Individual European countries (excluding the UK) have low impact relative to the USA or the UK on shock propagation. Nevertheless, the global financial network is highly susceptible to the shocks to the entire EA financial system despite the low sensitivity of individual European countries' shocks. The impact of the financial shock coming from the EA has a similar magnitude, in terms of number of countries affected and the speed of the shock propagation, to shocks origination from the USA or the UK shock. Another important development since 2009 is the rising role of the Asian countries and the significant increase in network susceptibility to shocks from China and Hong Kong SAR economies in 2015.

A few caveats to our analysis should be noted. Our data are limited to the use of aggregate countries' bilateral financial position data by instrument, as sectoral, currency, and maturity breakdowns are either limited or non-existed for a large number of countries. Additionally, the CDIS, CPIS, and the BIS do not integrate international and domestic holdings of different 
types of assets and liabilities and is on a residency basis that may not fully account for the ultimate risk.

Despite the data limitations, our results provide a possible and broad empirical foundation for the discussion of appropriate policy buffers and financial spillovers between countries. Nevertheless, to be able to offer a behavioral analysis of the channels through which shocks are transmitted in the global financial network, a theoretical model is needed to define thresholds and interlayer interactions, as well as to account for the pre-existing buffers to cushion shock propagation. Countries have different buffers and could introduce different policies to smooth the impact of an external shock or shock spillovers to/from other countries. Future work will explore the behavioral analysis of the channels through which shocks are propagated in the global financial network, as well as the identification of the impact of financial shocks on real economies domestically and abroad through trade and financial interlayers' coupling. 
Figure 6. Summary of the Contagion Dynamics in the Networks in 2015
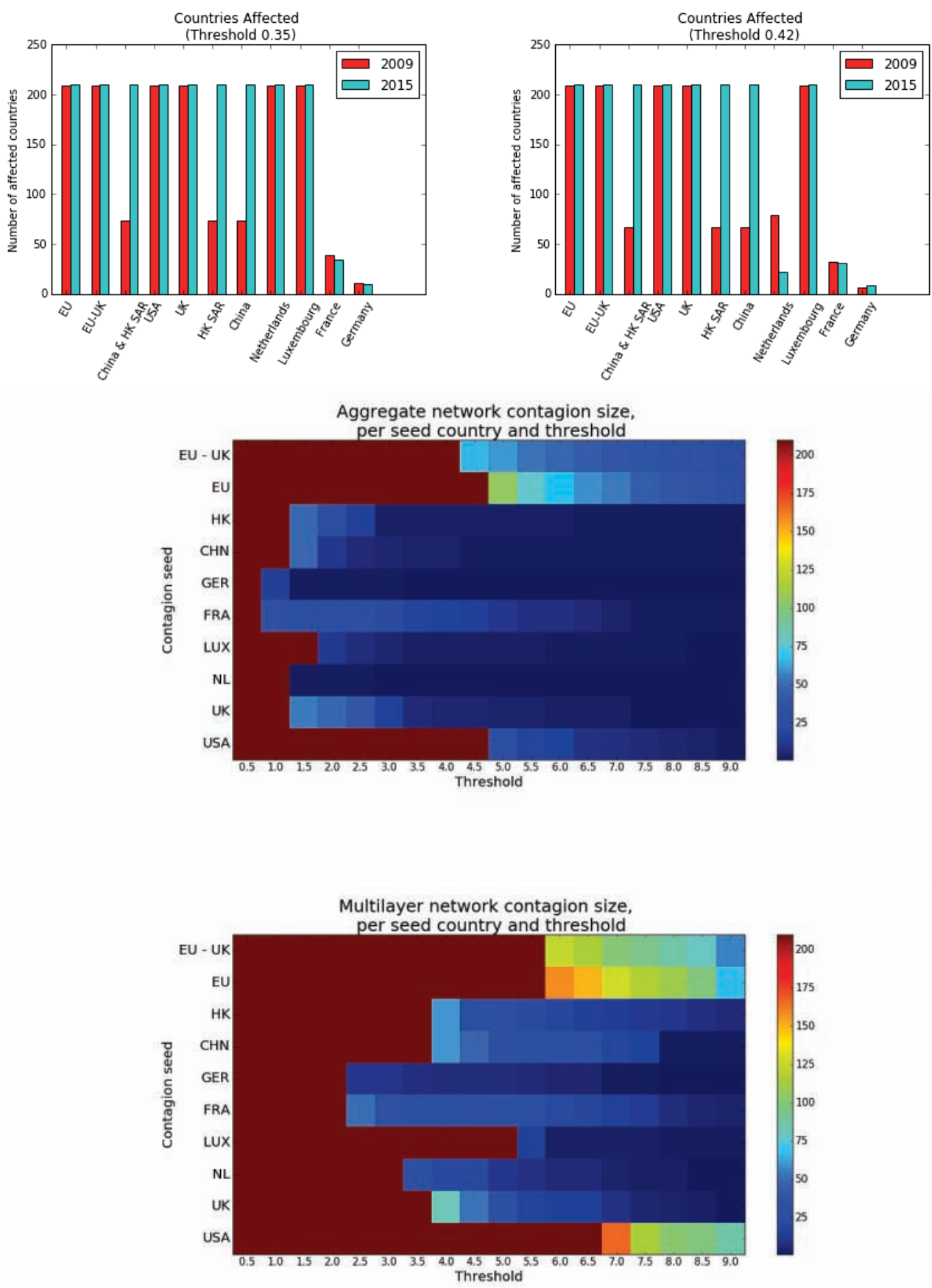

Source: IMF, BIS, authors' calculations. The bar charts show the total number of affected countries in the multiplex network for the threshold of 0.35 (left) and 0.42 (right), and consider immediate contagion between layers. For a threshold of 0.35 (35 percent) a shock to China is as strong as to the EA, the USA, or the UK. For a threshold of 0.42 (42 percent), the number of affected countries is smaller, however, the difference between 2009 and 2015 is noticeable. Likewise, the contours plots show - for the aggregate and multiplex networks - the number of affected countries for different contagion seeds and fine thresholds ( 0.5 difference). 


\section{REFERENCES}

Acemoglu, Daron, Asuman Ozdaglar, and Alireza Tahbaz-Salehi, 2015, "Systemic risk and stability in financial networks," The american economic review, Vol. 105, No. 2, pp. 564608.

Aghion, Philippe, George-Marios Angeletos, Abhijit Banerjee, and Kalina Manova, 2010, "Volatility and growth: Credit constraints and the composition of investment," Journal of Monetary Economics, Vol. 57, No. 3, pp. 246-265.

Allen, Franklin, and Douglas Gale, 2000, “Financial contagion," Journal of political economy, Vol. 108, No. 1, pp. 1-33.

Aoki, Kosuke, Gianluca Benigno, Nobuhiro Kiyotaki, and others, 2010, "Adjusting to Capital Account Liberalization,” Techn. rep., Centre for Economic Performance, LSE.

Artis, Michael, and Mathias Hoffmann, 2006, "The Home Bias and Capital Income Flows between Countries and Regions,” Techn. rep., CEPR Discussion Paper 5.

Artis, Michael J, and Mathias Hoffmann, 2009, "Declining home bias and the increase in international risk sharing," Building the Financial Foundations of the Euro.

Bargigli, Leonardo, Giovanni Di Iasio, Luigi Infante, Fabrizio Lillo, and Federico Pierobon, 2015, "The multiplex structure of interbank networks," Quantitative Finance, Vol. 15, No. 4, pp. 673-691.

Battiston, Federico, Vincenzo Nicosia, and Vito Latora, 2014, "Structural measures for multiplex networks," Physical Review E, Vol. 89, No. 3, p. 032804.

Battiston, Stefano, Michelangelo Puliga, Rahul Kaushik, Paolo Tasca, and Guido Caldarelli, 2012, "Debtrank: Too central to fail? financial networks, the fed and systemic risk," Scientific reports, Vol. 2, p. srep00541.

Benedictis, Nenci Silvia Santoni Gianluca Tajoli Lucia, Luca De, and Claudio Vicarelli, 2014, "Network Analysis of World Trade using the BACI-CEPII dataset," Global Economy Journal, , No. 14(3-4), pp. 287-343.

Blanchard, Olivier, Jonathan D Ostry, Atish R Ghosh, and Marcos Chamon, 2016, "Do Capital Flows Need to Be Tamed? Capital Flows: Expansionary or Contractionary?" The American Economic Review, Vol. 106, No. 5, pp. 565-569.

Bluhm, Ester Faia Jan Pieter Krahnen, Marcel, 2013, “Endogenous banks’ networks, cascades and systemic risk," Techn. rep., Techn. rep., Research Center SAFE-Sustainable Architecture for Finance in Europe, Goethe University Frankfurt.

Boccaletti, Stefano, Ginestra Bianconi, Regino Criado, Charo I Del Genio, Jesús GómezGardenes, Miguel Romance, Irene Sendina-Nadal, Zhen Wang, and Massimiliano Zanin, 2014, "The structure and dynamics of multilayer networks," Physics Reports, Vol. 544, No. 1, pp. 1-122.

Bonato, Anthony, 2008, A course on the web graph, Vol. 89 (American Mathematical Soc.). 
Brummitt, Charles D, and Teruyoshi Kobayashi, 2015, "Cascades in multiplex financial networks with debts of different seniority," Physical Review E, Vol. 91, No. 6, p. 062813.

Brummitt, Charles D, Kyu-Min Lee, and K-I Goh, 2012, "Multiplexity-facilitated cascades in networks," Physical Review E, Vol. 85, No. 4, p. 045102.

Cabrales, Antonio, Douglas Gale, and Piero Gottardi, 2015, "Financial Contagion in Networks," in The Oxford Handbook of the Economics of Networks.

Caccioli, Fabio, Munik Shrestha, Cristopher Moore, and J Doyne Farmer, 2014, "Stability analysis of financial contagion due to overlapping portfolios," Journal of Banking \& Finance, Vol. 46, pp. 233-245.

Carvalho, Vasco M, 2014, "From micro to macro via production networks," The Journal of Economic Perspectives, Vol. 28, No. 4, pp. 23-47.

Castrén, Olli, and Ilja Kristian Kavonius, 2009, "Balance Sheet Interlinkages and MacroFinancial Risk Analysis in the Euro Area,” Techn. rep., European Central Bank.

Cerina, Zhu Zhen Chessa Alessandro, Federica, and Massimo Riccaboni, 2014, "World Inputoutput network," PLoS ONE, , No. 10(7), p. e0134025.

Cerutti, Eugenio M, and Haonan Zhou, 2017, "The global banking network in the aftermath of the crisis: Is there evidence of de-globalization?" IMF Working Paper, , No. 17/232.

Chinazzi, Matteo, Giorgio Fagiolo, Javier A Reyes, and Stefano Schiavo, 2013, "Post-mortem examination of the international financial network," Journal of Economic Dynamics and Control, Vol. 37, No. 8, pp. 1692-1713.

Chung, Jong-Eun Lee Elena Loukoianova Hail Park, Kyuil, and Hyun Song Shin, 2014, "Global Liquidity through the Lens of Monetary Aggregates," IMF Working Paper, , No. $14 / 9$.

De Domenico, Manlio, Andrea Lancichinetti, Alex Arenas, and Martin Rosvall, 2015, "Identifying modular flows on multilayer networks reveals highly overlapping organization in interconnected systems," Physical Review X, Vol. 5, No. 1, p. 011027.

DeFord, Daryl R, and Scott D Pauls, 2015, "Network models that reflect multiplex dynamics," arXiv preprint arXiv:1507.00695.

Dell'Ariccia, Giovanni, Paolo Mauro, Andre Faria, Jonathan David Ostry, Julian Di Giovanni, Martin Schindler, Ayhan Kose, Marco Terrones, and others, 2008, "Reaping the Benefits of Financial Globalization,” Techn. rep., International Monetary Fund.

Dimond, Douglas W., and Philip H. Dybvig, 1983, "Bank Runs, Deposit Insurance, and Liquidity," The Journal of Political Economy, Vol. 91, No. 3, pp. 401-419.

Elliott, Matthew, Benjamin Golub, and Matthew O Jackson, 2014, "Financial networks and contagion," The American economic review, Vol. 104, No. 10, pp. 3115-3153.

Errico, Luca, Artak Harutyunyan, Elena Loukoianova, Richard Walton, Yevgeniya Korniyenko, Goran Amidzic, Hanan AbuShanab, Hyun Song Shin, and others, 2014, "Map- 
ping the Shadow Banking System Through a Global Flow of Funds Analysis," Techn. rep., International Monetary Fund.

Espinosa-Vega, Marco A, and Juan Solé, 2011, "Cross-border financial surveillance: a network perspective," Journal of Financial Economic Policy, Vol. 3, No. 3, pp. 182-205.

Faria, Andre, Paolo Mauro, Philip R Lane, and Gian Maria Milesi-Ferretti, 2007, "The shifting composition of external liabilities," Journal of the European Economic Association, Vol. 5, No. 2-3, pp. 480-490.

Forbes, Kristin, 2014, "Financial 'deglobalization'? capital flows, banks and the Beatles," speech to Queen Mary University, London, Vol. 18.

Forbes, Kristin, Dennis Reinhardt, and Tomasz Wieladek, 2017, “The spillovers, interactions, and (un) intended consequences of monetary and regulatory policies," Journal of Monetary Economics, Vol. 85, pp. 1-22.

Gabaix, Xavier, 2011, “The granular origins of aggregate fluctuations," Econometrica, Vol. 79, No. 3, pp. 733-772.

Gai, Prasanna, and Sujit Kapadia, 2010, "Contagion in financial networks," in Proceedings of the Royal Society of London A: Mathematical, Physical and Engineering Sciences, Vol. 466, pp. 2401-2423 (The Royal Society).

Ghosh, Atish R, Jonathan D Ostry, and Mahvash S Qureshi, 2016, "When do capital inflow surges end in tears?” The American Economic Review, Vol. 106, No. 5, pp. 581-585.

Glasserman, Paul, and H Peyton Young, 2015, "How likely is contagion in financial networks?" Journal of Banking \& Finance, Vol. 50, pp. 383-399.

Greenwood, Robin, Augustin Landier, and David Thesmar, 2015, "Vulnerable banks," Journal of Financial Economics, Vol. 115, No. 3, pp. 471-485.

Hale, Galina, 2012, "Bank relationships, business cycles, and financial crises," Journal of International Economics, Vol. 88, No. 2, pp. 312-325.

Hale, Galina, Tumer Kapan, Camelia Minoiu, and others, 2016, "Crisis transmission through the global banking network," Techn. rep., Federal Reserve Bank of San Francisc.

Hoggarth, Glen, Carsten Jung, and Dennis Reinhardt, 2016, "Capital inflowsâĂŤthe good, the bad and the bubbly," Techn. rep., Bank of England.

Kaltwasser, Pablo Rovira, and Alessandro Spelta, 2012, "Systemic risk in the interbank market with heterogenious agents," .

Kivelä, Mikko, Alex Arenas, Marc Barthelemy, James P Gleeson, Yamir Moreno, and Mason A Porter, 2014, "Multilayer networks," Journal of complex networks, Vol. 2, No. 3, pp. 203-271.

Kiyotaki, Nobuhiro, and John Moore, 2002, "Balance-sheet contagion," The American Economic Review, Vol. 92, No. 2, pp. 46-50. 
Kleinberg, Jon, 1999, "Hubs, Authorities, and Communities," ACM Computing Surveys, , No. 31(4).

Kok, Christoffer, and Mattia Montagna, 2013, "Multi-layered interbank model for assessing systemic Risk," Techn. rep., Kiel Institute for the World Economy.

Kose, M Ayhan, Eswar S Prasad, and Marco E Terrones, 2009, "Does financial globalization promote risk sharing?" Journal of Development Economics, Vol. 89, No. 2, pp. 258-270.

Kubelec, Chris, and Filipa Sa, 2010, “The geographical composition of national external balance sheets: 1980-2005," Techn. rep., Bank of England.

Lane, Philip R, 2015, “Cross-border financial linkages: Identifying and measuring vulnerabilities," CEPR Policy Insight, , No. 77.

Lane, Philip RR, and Gian Maria Maria Milesi-Ferretti, 2017, "International financial integration in the aftermath of the global financial crisis," .

Leon, Berndsen Ron, Carlos, and Luc Renneboog, 2014, "Financial Stability and Interacting Networks of Financial Institutions and Market Infrastructures," Borradores de Economia, , No. 848.

Lund, Susan, Toos Daruvala, Richard Dobbs, Philipp Härle, Ju-Hon Kwek, and Ricardo Falcón, 2013, "Financial globalization: Retreat or reset," McKinsey Global Institute, p. 2.

Mallaby, S, 2016, “Globalization resets,” Finance and Development, pp. 6-10.

Milesi-Ferretti, Gian-Maria, and Cédric Tille, 2011, "The great retrenchment: international capital flows during the global financial crisis," Economic Policy, Vol. 26, No. 66, pp. 289-346.

Minoiu, Camelia, and Javier A Reyes, 2013, "A network analysis of global banking: 19782010,” Journal of Financial Stability, Vol. 9, No. 2, pp. 168-184.

Neagu, Florian, and Irina Mihai, 2013, "Sudden stop of capital flows and the consequences for the banking sector and the real economy," Techn. rep., European Central Bank.

Newman, Mark, 2010, Networks: an introduction (Oxford university press).

Poledna, Sebastian, José Luis Molina-Borboa, Serafín Martínez-Jaramillo, Marco Van Der Leij, and Stefan Thurner, 2015, "The multi-layer network nature of systemic risk and its implications for the costs of financial crises," Journal of Financial Stability, Vol. 20, pp. 70-81.

Salehi, Mostafa, Rajesh Sharma, Moreno Marzolla, Matteo Magnani, Payam Siyari, and Danilo Montesi, 2015, "Spreading processes in multilayer networks," IEEE Transactions on Network Science and Engineering, Vol. 2, No. 2, pp. 65-83.

Turner, Philip, 2014, “The global long-term interest rate, financial risks and policy choices in EMEs," BIS Working Paper, , No. 441.

Watts, Duncan J, 2002, “A simple model of global cascades on random networks," Proceedings of the National Academy of Sciences, Vol. 99, No. 9, pp. 5766-5771. 
WEO, IMF, 2014, “World Economic Outlook,” Washington: International Monetary Fund. 
Appendix A. Immediate Countries AFFeCted due to Shocks

Table A.1. Countries and Economies Exposed to and Affected by China Shock in 2015.

\begin{tabular}{|c|c|c|c|}
\hline & \multirow[b]{2}{*}{ Country } & \multicolumn{2}{|c|}{ Proportion of China in: } \\
\hline & & Total claims & FDI-equity claims \\
\hline 1 & American Samoa & $99 \%$ & $99 \%$ \\
\hline 2 & Samoa & $68 \%$ & $99 \%$ \\
\hline 3 & Brunei Darussalam & $34 \%$ & $98 \%$ \\
\hline 4 & Hong Kong SAR & $33 \%$ & $47 \%$ \\
\hline 5 & Benin & $32 \%$ & $69 \%$ \\
\hline 6 & China P.R.: Macao & $31 \%$ & $43 \%$ \\
\hline 7 & Swaziland & $25 \%$ & $44 \%$ \\
\hline 8 & US Virgin Islands & $24 \%$ & $54 \%$ \\
\hline 9 & Liberia & $24 \%$ & $48 \%$ \\
\hline 10 & South Africa & $19 \%$ & $42 \%$ \\
\hline 11 & Myanmar & $18 \%$ & $80 \%$ \\
\hline 12 & US Pacific Islands & $16 \%$ & $86 \%$ \\
\hline 13 & Barbados & $16 \%$ & $71 \%$ \\
\hline 14 & Seychelles & $16 \%$ & $42 \%$ \\
\hline 15 & Taiwan Province of China & $12 \%$ & $54 \%$ \\
\hline 16 & Indonesia & $11 \%$ & $57 \%$ \\
\hline 17 & Vanuatu & $9 \%$ & $95 \%$ \\
\hline 18 & Tonga & $7 \%$ & $100 \%$ \\
\hline 19 & Mongolia & $6 \%$ & $49 \%$ \\
\hline 20 & Cuba & $4 \%$ & $77 \%$ \\
\hline 21 & Cambodia & $3 \%$ & $76 \%$ \\
\hline 22 & Niger & $3 \%$ & $49 \%$ \\
\hline 23 & St. Kitts and Nevis & $3 \%$ & $48 \%$ \\
\hline 24 & Djibouti & $1 \%$ & $93 \%$ \\
\hline 25 & Bhutan & $1 \%$ & $87 \%$ \\
\hline 26 & West Bank and Gaza & $1 \%$ & $48 \%$ \\
\hline 27 & Lao People's Democratic Republic & $1 \%$ & $42 \%$ \\
\hline 28 & Haiti & $1 \%$ & $83 \%$ \\
\hline 29 & Rwanda & $1 \%$ & $62 \%$ \\
\hline
\end{tabular}

Source: IMF, BIS, authors' calculations. The table shows the percentage of country's total claims and total direct investment in debt claims in China. Numbers shown in red are for countries with total claims above the 35 percent threshold that would be in financial distress. 


\section{Appendix B. The Multilayer network FrameWork}

\section{B.1. Multilayer Network Formalism and Introduction of Notation}

A network $(G=\{V, E\})$ is defined as a set of nodes $V$ and a set edges $E$. Edges represent an interaction between two nodes. A multilayer network is a representation of a network, with different types of interactions (edges). In this representation, nodes are present in different layers and in each layer edges represent certain type of interactions. Therefore, nodes in a multilayer network are represented by a node-layer tuple $((i, \alpha))$, where $i$ is the index of the node and $\alpha$ the index of the layer (Kivelä and others, 2014). In this paper, we follow the convention that Latin letters denote nodes and Greek letters - layers. A node may be in more than one layer and edges can link nodes in the same or different layers. We are focusing on multiplex networks which are a special type of multilayer networks and have the constraint that the only possible interlayer edges are ones in which a given node in one layer is connected to the same node in the other layers. Additionally, we require the multiplex network to be node-aligned, meaning that all nodes must be present in all layers.

The notations are introduced below:

A multiplex network is composed by nodes, layers and edges. Edges are represented by a tuple of node-layer tuples, for example an edge from node $i$ in layer $\alpha$ to node $j$ in layer $\alpha$ is denoted by $((i, \alpha),(j, \alpha))$. Edges have assigned weights to them and we denote them by $\omega_{j \beta}^{i \alpha}$. The adjacency tensor $M_{i \alpha}^{j \beta}$ has all the information of the multiplex network and its components are given by:

$$
M_{j \beta}^{i \alpha}= \begin{cases}\omega_{j \beta}^{i \alpha}, & (i \alpha, j \beta) \in E, \\ 0, & (i \alpha, j \beta) \notin E .\end{cases}
$$

We denote the number of nodes by $n$ and the number of layers by $l$. For directed networks we consider $M_{j \beta}^{i \alpha}$ to correspond to the edge which starts in $(i, \alpha)$ and ends in $(j, \beta)$. We note that each layer of the multiplex network represents a different type of interaction and not a different time. All multiplex networks in this work are static - represent only one year.

\section{B.2. Mapping of Data into the Multiplex Network}

The mapping of financial data into networks has been studied before by (Gai and Kapadia, 2010). In their mapping, countries represent nodes and a directed edge $(i, j)$ denotes financial 
amount owed by country $i$ to country $j$. The amount of the debt owed is equal to the weight of the edge $\left(\omega_{i j}\right)$. We follow similar convention for intralayer edges. We consider five types of financial instruments and each corresponds to a layer: direct investment debt and equity, portfolio investment debt and equity, and banking loans and deposits. Figure 7 shows a schematic diagram of the multiplex network and its layers.

\section{Figure 7. Schematic Representation of a Multiplex and Aggregated Networks of the Global Financial System}
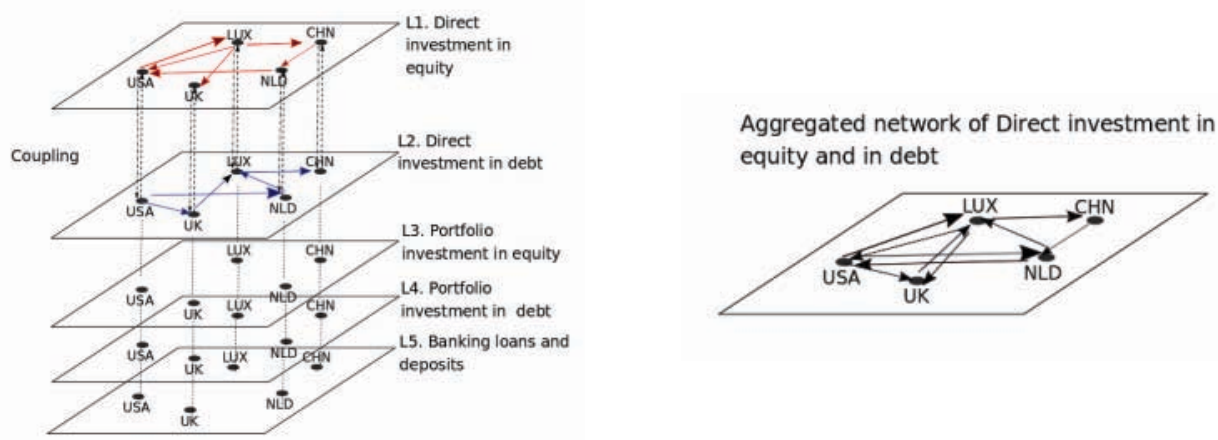

Note: On the left, we show a schematic representation of a multiplex global financial network where each of five layers corresponds to a different type of financial holding (direct investment in equity, direct investment in debt, portfolio investment in equity, portfolio investment in debt, and banking loans and deposits). For example, in the network, the red edges correspond to direct investment in equity while the blue edges correspond to direct investment in debt. For simplicity, only these two layers are illustrated. Between the layers there are directed interlayer edges, whose weights are given by the coupling rule. On the right, we show a schematic network that corresponds to the aggregation of the first two layers (direct investments in equity and debt). When two edges (with same direction) overlap the weights are summed up and a single edge is kept.

Assigning weights to interlayer edges - also referred to as the coupling - is not straightforward. For example, in previous work on multiplex trade networks - where nodes correspond to countries and layers correspond to trade flows of different commodities - the coupling $\left(M_{i \alpha}^{i \beta}\right)$ is defined as the proportion of a quantity of a good at node $i$ on layer $\beta$ that passes through to layer $\alpha$ (DeFord and Pauls, 2015). We take a similar approach, considering the coupling to be the flow of assets at risk of a default. However, we do not calculate the proportion between assets at risk in one layer and another since all layers have the same monetary unit and we consider it important to preserve the different magnitudes of financial positions. In this sense the in-degree of a node is the total amount of assets that are at risk of a default. A country in one layer could propagate the shock to countries in other layers through directed edges, therefore the shock from a node-layer $(i, \beta)$ that is propagated to a node $(i, \alpha)$ is the total in-degree of a node $(i, \beta)$. This allows us to define the following coupling: 


$$
M_{i \alpha}^{i \beta}=\sum_{j} A_{j i}^{\beta}=\sum_{j} M_{i \beta}^{j \beta}=M_{i \beta}^{j \beta} u_{j} .
$$

where $u$ is a 1 vector of dimension $n \times 1$ assuming implicit Einstein sum notation. We will refer to this weighting of interlayer edges as the Risk flow coupling.

\section{B.3. The Aggregated Network}

The use of the multiplex framework allows us to consider different types of interactions - in this research different types of financial instruments. To show the relevance of this representation we compare our results to those that would have been obtained in the aggregated or the monoplex network framework. The monoplex network or aggregated network is obtained by summing up across all types of financial instruments (direct investment in equity, direct investment in debt, portfolio investment in equity, portfolio investment in debt, and banking loans and deposits) between two countries and assigning edges between the countries correspondingly, preserving the edges direction (from debtor to creditor). An example of the aggregation between two layers is shown on Figure 7 (the network on the right). The adjacency matrix of the aggregated network can be obtained from the multiplex adjacency matrix by the following procedure:

$$
A_{i j}=\sum_{\alpha} M_{j \alpha}^{i \alpha}
$$

In this paper, we refer to the monoplex projection of the multiplex network as the aggregated network.

\section{B.4. Structural Network Measures}

The dynamics of spreading process on networks are influenced by the structure of the network. In this section, we define centrality measures which have been generalized for the multiplex framework and used for the purpose of this research.

Some structural network measures are naturally extrapolated in the mutliplex framework (Battiston, Nicosia, and Latora, 2014), for example, the strength of node $i$ on layer $\alpha$ is given by $s_{i}^{[\alpha]}=\sum_{j} \omega_{i j}^{[\alpha]}$. Similar is true for in and out strength. The generalization of eigenvector centrality and PageRank centrality measures is not straight forward and has been extrapo- 
lated differently (we follow approach used by (De Domenico and others, 2015)). We use the Einstein sum notation as generalization for the multiplex centrality measures:

- Eigenvector centrality: In network theory eigenvector centrality is a measure of the influence of a node in a network. The eigenvector centrality of node $i$ is given by the $i$-th entrance of eigenvector $\overrightarrow{v_{1}}$ of the adjacency matrix, where $\overrightarrow{v_{1}}$ is the eigenvector with corresponding largest eigenvalue. For the multiplex network, the eigenvector centrality has been expanded to account for an analogous eigentensor equation shown below (De Domenico and others, 2015):

$$
M_{j \beta}^{i \alpha} \Theta_{i \alpha}=\lambda_{1} \Theta_{i \alpha}
$$

Where $\lambda_{1}$ is the largest eigenvalue. Then, the eigenvector centrality of node $i$ in layer $\alpha$ is given by $\Theta_{i \alpha}$. The overall eigenvector centrality of node $i$ is given by $\sum_{\alpha} \Theta_{i \alpha}$. This problem can also be reduced into the supra-adjacency matrix framework where a tensor is flattened into a $n l \times n l$ matrix. The eigenvector of this supradjacency matrix has the eigenvector centrality of each node-layer. To obtain the total eigenvector centrality of a node in a multiplex network it is sufficient to sum among all layers. We do not use eigenvector centrality for our work since the direction of edges is important to us. Instead, we consider PageRank centrality and hubs and authorities centrality measures explained below.

- Hubs and authorities: Hyperlink-Induced Topic Search (HITS centrality, also known as hubs and authorities centrality) was developed by Kleinberg (1999) to rank websites which reference each other. The idea behind is that certain webpages known as hubs, served as large directories that point to authoritative pages which have the information people usually look for. The centrality measure is reduced to the vector with largest eigenvalue of a modified adjacency matrix (Bonato, 2008). In the multiplex framework the same spectral properties can be computed as shown below:

$$
\begin{gathered}
M_{j \beta}^{i \alpha} M_{j \beta}^{i \alpha T} \Gamma_{i \alpha}=\lambda_{1} \Gamma_{j \beta} \\
M_{j \beta}^{i \alpha T} M_{j \beta}^{i \alpha} \Upsilon_{i \alpha}=\Upsilon_{j \beta}
\end{gathered}
$$

where ${ }^{T}$ denotes the transpose tensor. The leading eigenvectors $\Gamma_{i \alpha}$ and $\Upsilon_{i \alpha}$ have the hub and authority score of each node respectively. In the framework we use, the interpretation of hubs and authorities is extrapolated to debtors and creditors. Since an incoming link from node $i$ to node $j$ implies that node $i$ owes financial obligations to node $j$ (hubs 
centrality measure). We note that if the direction of edges is inverted the hubs score corresponds to the authority score of the original network and vice versa.

- PageRank: PageRank is the most widely used centrality measure and consists of computing the probability of being at the node in the steady state of a teleporting random walk. In the multiplex framework, it can be represented by the following eigentensor equation:

$$
R_{j \beta}^{i \alpha}=r T_{j \beta}^{i \alpha}+\frac{1-r}{N L} u_{j \beta}^{i \alpha}
$$

where $T_{j \beta}^{i \alpha}$ is the transition probability tensor used in the benchmark random walk in networks, that is with equal probability the walker jumps to an adjacent neighbor. The second part of the equation accounts for the teletransportation parameter. For our calculations we will use the benchmark parameter $r=0.85$. With the direction of edges we defined (from debtor to creditor) PageRank ranks nodes according to their role as creditors in the network. However, for our analysis it is also important to rank nodes according to their roles as debtors - which is done by inverting the original matrix. In this sense, we abuse nomenclature and define two PageRank measures for our multiplex networks:

- Creditor PageRank centrality: we refer to the PageRank of the multiplex network with direction of edges (from debtor to creditor) as defined in the data section and by solving equation (7).

- Debtor PageRank centrality: we refer to the PageRank of the multiplex network with inverse direction of edges (from creditor to debtor). That is, we consider the transpose of the adjacency tensor $\left(M_{j \beta}^{i \alpha T}\right)$ for computing the transition probability tensor included in equation (7).

It is important to note, that for weighted multiplex networks the coupling (i.e. weight of the edge linking the same node in two layers) has an impact on the calculation of the centrality measures explained above.

\section{Appendix C. Multiplex Contagion model and Simulation}

The threshold model used in this research assigns to each node one of two possible states: "healthy" or "defaulted", in mathematical terms the state of node $i$ at discrete time step $\tau$ is given by $\sigma_{i}(\tau)$ and it is equal to 0 when "healthy" and 1 when "defaulted". The model is closely related to the Watts threshold model (Watts, 2002) where each node $i$ has an initial 
threshold $\phi_{i} \in[0,1]$, which does not change over time. At an initial time step all nodes are "healthy" except for a seed node $s$ which is "defaulted". The seed is considered to have zero threshold (i.e. $\phi_{s}=0$ ). Thereafter a node changes its state from "healthy" to "defaulted" if the fraction of incoming links from defaulted neighbors is above the threshold of the node this is known as the updating rule. Our approach for the monolplex or aggregated network follows the same logic but since the network is weighted and directed we consider the fraction of weighted indegree coming from a defaulted neighbor for the updating rule, that is:

$$
\sigma_{i}(\tau)= \begin{cases}1, & \frac{m_{i}^{-}(\tau-1)}{k_{i}^{-}}>\phi \\ 0, & \text { otherwise }\end{cases}
$$

where $m_{i}^{-}(\tau-1)=\sum_{j} A_{j i} \sigma_{j}(\tau-1)$ is the sum of weights of defaulted (in-)neighbors of $i$ at time $\tau$ and $k_{i}^{-}=\sum_{j} A_{j i}$ the weighted in-degree of $i$.

Similarly, for the multiplex network we consider the state of node-layer $(i, \alpha)$ to be given by $\sigma_{i, \alpha}$. The updating rule is as before - we calculate the fraction of weighted indegree edges coming from defaulted nodes in the same layer and use the additional condition that the counterpart of a node in another layer has defaulted - in this case the node will become defaulted. Mathematically that is:

$$
\sigma_{i, \alpha}(\tau)= \begin{cases}1, & \frac{m_{i \alpha}^{-}(\tau-1)}{k_{i \alpha}^{-}}>\phi_{i} \\ 1, & \sigma_{i, \alpha}(\tau-1)=1, \text { for any } \beta \\ 0, & \text { otherwise }\end{cases}
$$

where $m_{i \alpha}^{-}(\tau-1)=\sum_{j} M_{i \alpha}^{j \alpha} \sigma_{j \alpha}(\tau-1)$ and $k_{i \alpha}^{-}=\sum_{j} M_{i \alpha}^{j \alpha}$ are generalizations of the monoplex case.

This model was studied via simulations, where different countries or group of countries were selected as seeds for different simulations. For each initialization the selected seed(s) was(were) set to the "defaulted" state and the propagation of the shock was run in discrete time steps. The threshold $\phi_{i}$ is fixed at a certain level and is the same for all nodes except the seed(s) for a simulation. The simulation ends when no node changes its state. At the end, the number of nodes that have defaulted as a result of model simulation were counted. Total number of defaulted nodes measures the impact a shock from a given country has on the global financial network. Multiple simulations were done for different seed countries and different thresholds levels for both the aggregated and the multiplex networks. The results of the simulations for the aggregated and multiplex networks are featured in Figures 4-6. 


\section{APPENDIX D. OThER RESULTS OF CENTRALITY MEASURES}

\section{D.1. Multiplex Hubs and Authorities Ranking}

Table D.1.1. Hubs and Authorities Centrality Measures

\begin{tabular}{|c|c|c|c|c|}
\hline Rank & Aggregated hub & Multiplex hub & Aggregated authority & Multiplex authority \\
\hline 1 & United States & United States & United States & Luxembourg \\
\hline 2 & United Kingdom & Netherlands & Luxembourg & United States \\
\hline 3 & Netherlands & United Kingdom & United Kingdom & Netherlands \\
\hline 4 & Cayman Islands & Luxembourg & Japan & Germany \\
\hline 5 & Luxembourg & Ireland & Netherlands & United Kingdom \\
\hline 6 & France & Switzerland & Germany & Japan \\
\hline 7 & Germany & Canada & France & France \\
\hline 8 & Ireland & Bermuda & Canada & Ireland \\
\hline 9 & Japan & Belgium & Ireland & Switzerland \\
\hline 10 & Canada & Singapore & Cayman Islands & Canada \\
\hline 11 & Switzerland & Germany & Switzerland & Bermuda \\
\hline 12 & Australia & Cayman Islands & Hong Kong SAR & Belgium \\
\hline 13 & Italy & France & Belgium & Spain \\
\hline 14 & Bermuda & China & Italy & Italy \\
\hline 15 & Spain & Brazil & Bermuda & Cayman Islands \\
\hline 16 & Belgium & Spain & Norway & Hong Kong SAR \\
\hline 17 & China & Hong Kong SAR & Singapore & Jersey \\
\hline 18 & Hong Kong SAR & Australia & Australia & Virgin Islands, British \\
\hline 19 & Singapore & Mexico & Taiwan & Sweden \\
\hline 20 & Brazil & Sub-Saharan Africa & Spain & Gibraltar \\
\hline
\end{tabular}

\section{D.2. PageRank Creditor and Debtor Centrality (Measures for selected countries in each layer over time)}

Figures 8 to 11 show the development of the PageRank creditor and debtor centrality measures over time for selected countries and economies - China, Hong Kong SAR, France, Luxembourg, Netherlands, the UK and the USA. The centrality measures for the UK and the USA are significantly different compare to other countries, therefore, on Figure 10 and 11 they are excluded from the sample. 
Figure 8. Creditor PageRank Score
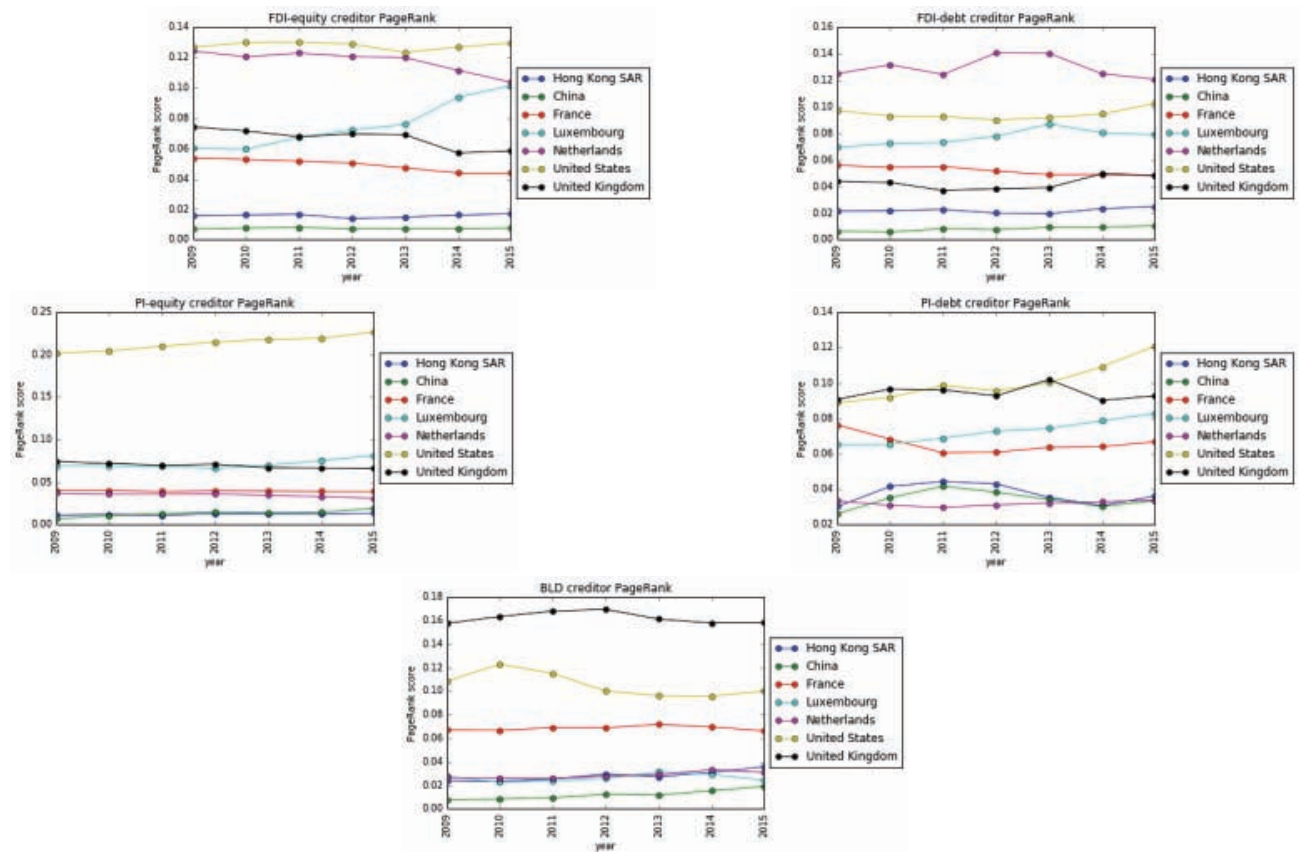

Source: IMF, BIS, authors' calculations. Each figure shows the development of the PageRank score for a different layer over time.

Figure 9. Debtor PageRank Score

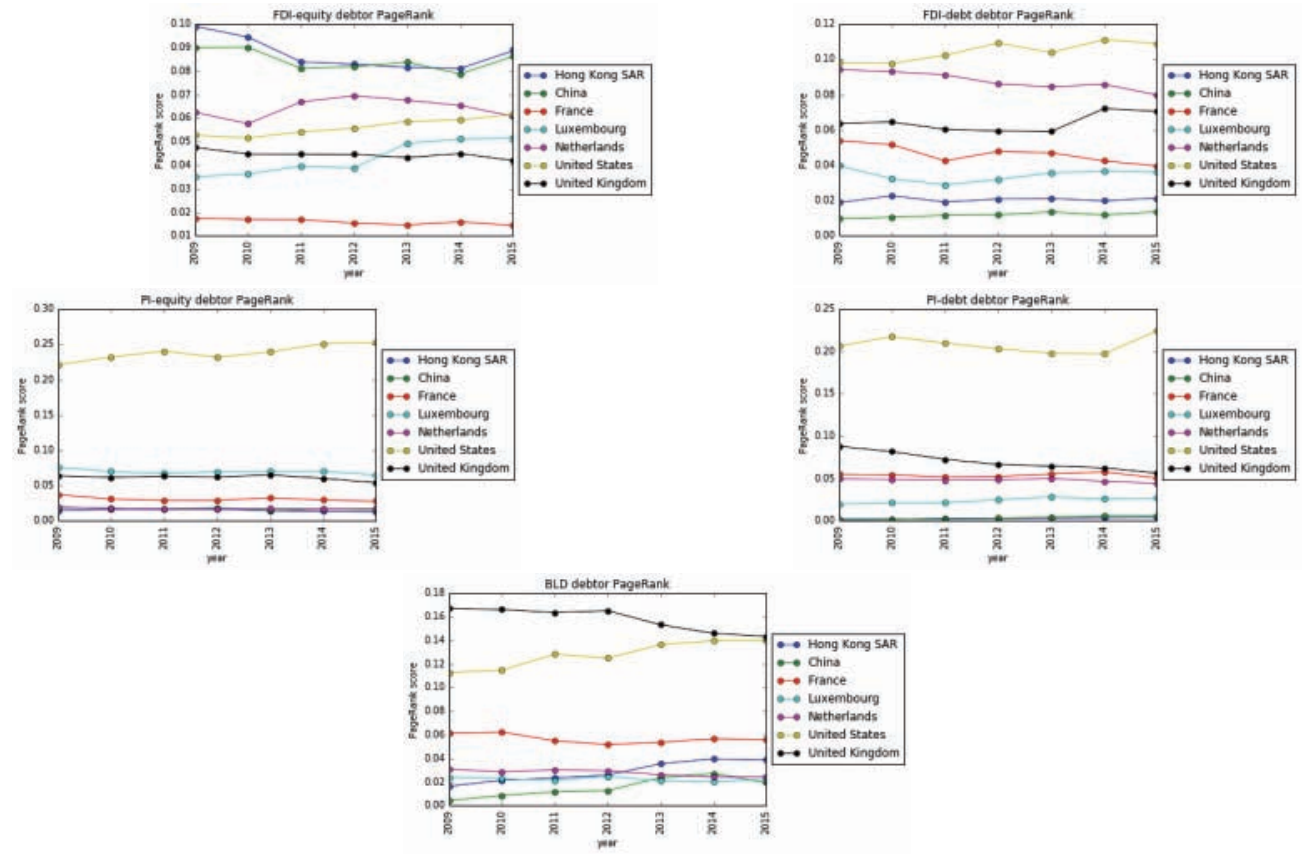

Source: IMF, BIS, authors' calculations. Each figure shows the development of the PageRank score for a different layer over time. 
Figure 10. Creditor PageRank Score Excluding USA and UK
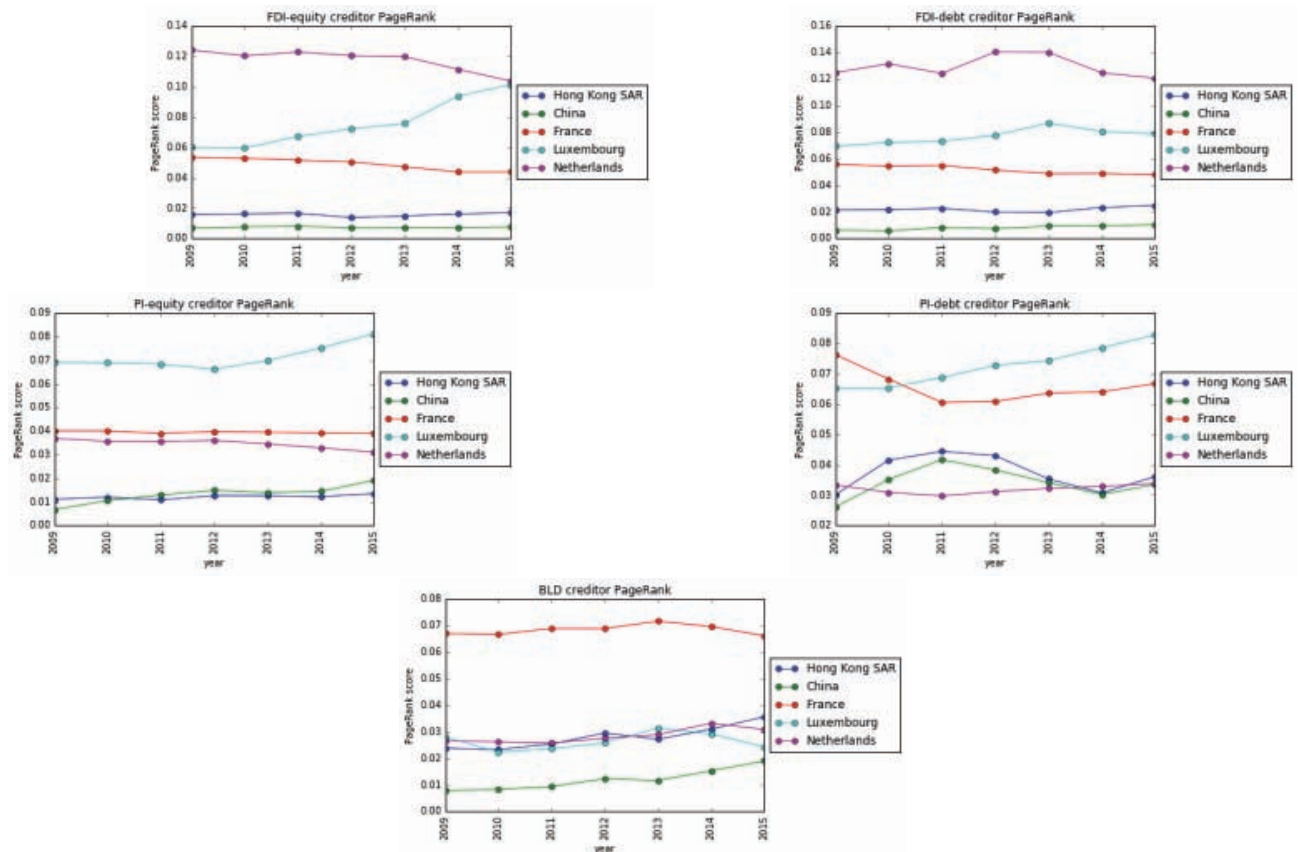

Source: IMF, BIS, authors' calculations. Each figure shows the development of the PageRank score for a different layer over time.

Figure 11. Debtor PageRank Score Excluding USA and UK
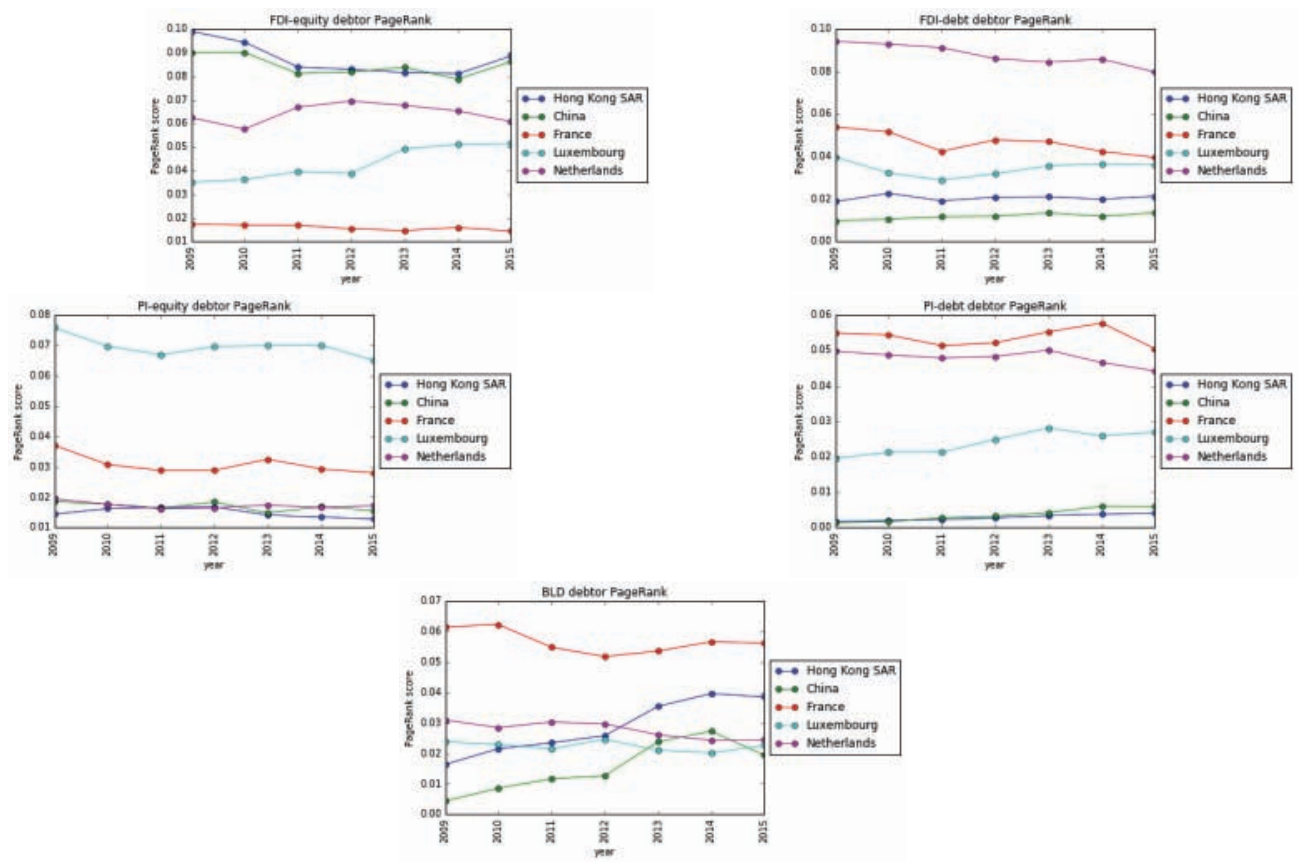

Source: IMF, BIS, authors' calculations. Each figure shows the development of the PageRank score for a different layer over time. 